This document was prepared in conjunction with work accomplished under Contract No. DE-AC09-96SR18500 with the U. S. Department of Energy.

\title{
DISCLAIMER
}

This report was prepared as an account of work sponsored by an agency of the United States Government. Neither the United States Government nor any agency thereof, nor any of their employees, makes any warranty, express or implied, or assumes any legal liability or responsibility for the accuracy, completeness, or usefulness of any information, apparatus, product or process disclosed, or represents that its use would not infringe privately owned rights. Reference herein to any specific commercial product, process or service by trade name, trademark, manufacturer, or otherwise does not necessarily constitute or imply its endorsement, recommendation, or favoring by the United States Government or any agency thereof. The views and opinions of authors expressed herein do not necessarily state or reflect those of the United States Government or any agency thereof.

This report has been reproduced directly from the best available copy.

Available for sale to the public, in paper, from: U.S. Department of Commerce, National Technical Information Service, 5285 Port Royal Road, Springfield, VA 22161, phone: (800) 553-6847, fax: (703) 605-6900

email: orders@ ntis.fedworld.gov

online ordering: http://www.ntis.gov/support/index.html

Available electronically at http://www.doe.gov/bridge

Available for a processing fee to U.S. Department of Energy and its contractors, in paper, from: U.S. Department of Energy, Office of Scientific and Technical Information, P.O. Box 62, Oak Ridge, TN 37831-0062,

phone: (865)576-8401,

fax: (865)576-5728

email: $\underline{\text { reports@ adonis.osti.gov }}$ 
WSRC-TR-2001-00583

Revision 0

Key Words: Salt Disposition

Plutonium, Uranium, Neptunium, HLW, Ion Exchange

\section{Alternate Sorbents for the Pretreatment of Tank Waste}

Attached is the final technical report submitted by Dr. Abraham Clearfield of the Texas A \& M University for work performed under Task Order Agreement \# KF92338-O, ERDA Subcontract \# C001571-O. This report is the final deliverable required under the task order agreement.

TAMU researchers synthesized three different types of sorbents; sodium nonatitanate $\left(\mathrm{Na}_{4} \mathrm{Ti}_{9} \mathrm{O}_{20} \times \mathrm{HH}_{2} \mathrm{O}\right.$ ), sodium titanosilicate of the ideal composition $\mathrm{Na}_{2} \mathrm{Ti}_{2} \mathrm{O}_{3} \mathrm{SiO}_{4} 2 \mathrm{H}_{2} \mathrm{O}$ and a pharmacosiderite of general formula, $\mathrm{M}_{3} \mathrm{H}(\mathrm{TiO})_{4}\left(\mathrm{SiO}_{4}\right)_{3} \cdot 4 \mathrm{H}_{2} \mathrm{O}$, where $\mathrm{M}=\mathrm{Na}, \mathrm{K}$. Strontium and actinide removal characteristics indicated that the sodium nonatitanate and pharmacosiderite materials performed as well as or better than the current Salt Processing facility baseline material, monosodium titanate (MST). The titanosilicate material exhibited relatively poor strontium and actinide removal characteristics under the strongly alkaline conditions. 
WSRC-TR-2001-00583

Revision 0

Approvals:

$\frac{\text { D. } 1.0 \mathrm{~S} L}{12 / 4 / 01}$

$\frac{12 / 4 / 2001}{\text { Date }}$

S. D. Fink, Level 4 Manager and TFA Lead

$\frac{R_{\varepsilon} \varepsilon_{1} d_{s}}{12 / 12 / 01}$
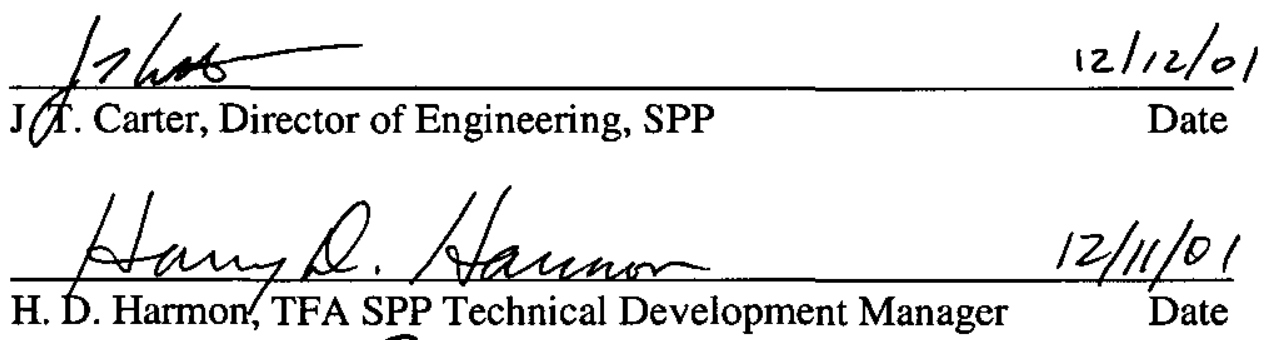

H. D. Harmon, TFA SPP Technical Development Manager Date

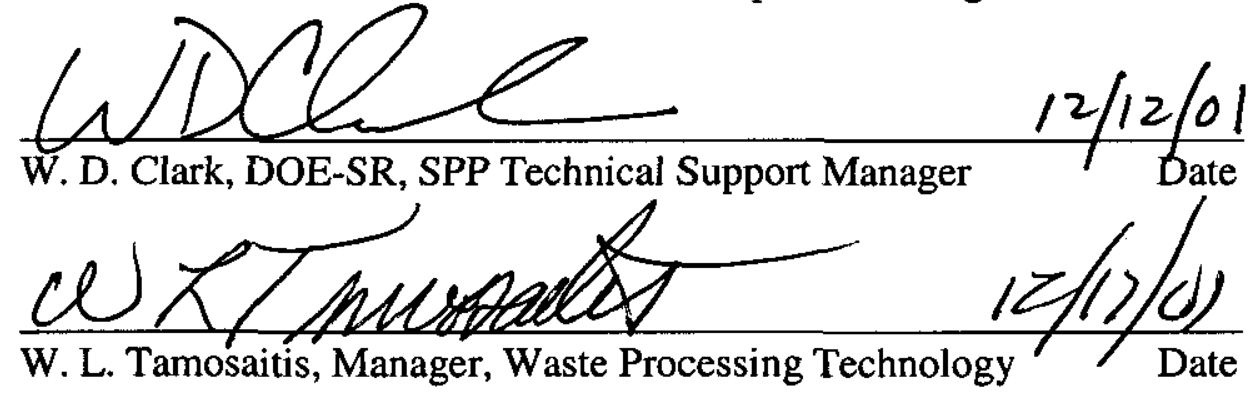


Development of Strontium and Actinide Specific Ion Exchangers for

Nuclear Waste Remediation

ERDA Grant No. C001571-O

\author{
Abraham Clearfield \\ Department of Chemistry \\ Texas A\&M University \\ College Station, Texas 77842
}

\author{
Co-Workers: \\ Dmitri Medvedev - Graduate Student \\ Dr. Xiang Ouyang - Post-doctoral Associate \\ Dr. Joy Heising - Post-doctoral Associate
}

Melissa Wierzbicki - Undergraduate Scholar

October 1, 2001 
WSRC-TR-2001-00583

\section{Executive Summary}

Several different types of sorbents have been synthesized and submitted to WSRC for testing in the removal of $\mathrm{Sr}$ and several actinides from Savannah River nuclear waste solutions. The samples include several forms of sodium nonatitanate, $\mathrm{Na}_{4} \mathrm{Ti}_{9} \mathrm{O}_{20} \cdot x \mathrm{H}_{2} \mathrm{O}$, a semi-crystalline sodium titanosilicate (CST) of ideal composition $\mathrm{Na}_{2} \mathrm{Ti}_{2} \mathrm{O}_{3} \mathrm{SiO}_{4} \cdot 2 \mathrm{H}_{2} \mathrm{O}$ and pharmacosiderites of general formula $\mathrm{M}_{3} \mathrm{H}(\mathrm{TiO})_{4}\left(\mathrm{SiO}_{4}\right)_{3} \cdot 4 \mathrm{H}_{2} \mathrm{O}, \mathrm{M}=\mathrm{Na}^{+}, \mathrm{K}^{+}$. Results of screening tests at the Savannah River Site showed that the nonatitanate samples exhibited as good, or better, performance than the monosodium titanate samples (MST) proposed for the treatment process. The sodium pharmacosiderite achieved very high sorption of strontium and actinides and should be examined in greater detail. None of the CST samples, whether crystalline (UOP preparations) or semi-crystalline (submitted in this study), were particularly effective in removal of the radioactive species, although the semi-crystalline product out-performed the crystalline samples.

It is recommended that the final removal process take advantage of the kinetics of the sorption reactions. The vast bulk of the uptake of strontium and the actinides occurs in the first two to three hours after the addition of the sorbents to the waste solution. By utilizing a double precipitation method on smaller batches, the first filtration may take place after a 2-3 hour hold time followed by a second addition of sorbent and a 3-4 hour hold time to reach acceptable levels of removal of the radioactive species in place of $168 \mathrm{~h}$ equilibration or the $24 \mathrm{~h}$ baseline. Such a procedure should increase the throughput of treated waste. 
WSRC-TR-2001-00583

\section{Objectives:}

1. Synthesize inorganic ion exchangers directed towards the removal $\mathrm{Sr}^{2+}$ from Savannah River (SR) supernatant high-level wastes.

2. Examine the structures of the ion exchangers and relate the structures to the ability to sequester the strontium and actinide ions in the waste systems.

\section{Introduction}

Three groups of compounds were chosen for synthesis, determination of ion exchange behavior in waste simulants and testing. They are sodium titanium silicate popularly designated as CST, titanium silicates with pharmacosiderite structure, and semi-crystalline sodium nonatitanates, $\mathrm{Na}_{4} \mathrm{Ti}_{9} \mathrm{O}_{20}$. All three have been previously shown to exhibit a high selectivity for strontium. A brief description of the three exchangers follows:

CST: The ideal formula for this compound is $\mathrm{Na}_{2} \mathrm{Ti}_{2} \mathrm{O}_{3}\left(\mathrm{SiO}_{4}\right) \cdot 2 \mathrm{H}_{2} \mathrm{O}$. The crystals are tetragonal: $a=7.8082(2), c=11.9735(4) \AA$, space group $\mathrm{P} 4_{2} / \mathrm{mcm}$ and $\mathrm{Z}=4$. The titanium atoms occur in clusters of four grouped about a $4_{2}$ axis, two up and two down, rotated by $90^{\circ}$. Each titanium is octahedrally coordinated, sharing edges in such a way that an inner core of four oxygens and four $\mathrm{Ti}$ atoms form a distorted cubane-like structure (Figure 1).[1] These cubanetype structures are bridged to each other through silicate groups along the a- and b-axis directions. The titanium-oxygen clusters are $7.81 \AA$ apart in both the a- and b-axis directions with the $\mathrm{Si}$ atoms at $\mathrm{c}=1 / 4$ and $3 / 4$. In the $\mathrm{c}$-axis direction, the $\mathrm{Ti}$ atoms are bridged by oxogroups. The c-axis is approximately $12 \AA$ long, which is twice the distance from the center of one cubane-like cluster to its neighbor in the c-axis direction. These two views of the framework are shown in Figures 2 and $\mathbf{3}$. 
WSRC-TR-2001-00583

The net result of this framework arrangement is that tunnels which form are onedimensional, running along the c-axis direction. Perpendicular to the tunnels are vacancies in the faces of four sides of the tunnels. These cavities are just the right size to enclose sodium ions. Four silicate oxygens bond to the sodium ion at a distance of $2.414(5) \AA$ (Figure 3). The sodium ion coordination is completed by bonding to two water molecules in the tunnels at a bond distance of $\mathrm{Na}-\mathrm{O}$ of $2.765(1) \AA$. Half the $\mathrm{Na}^{+}$ions are thus accounted for in the framework sites, as there are two sodiums in each face, over one c-axis cell length for a total of four out of the eight required per unit cell. The remaining sodiums reside within the tunnels along with the water molecules.

The Na-O bond distances within the tunnels are longer than the sum of the ionic radii

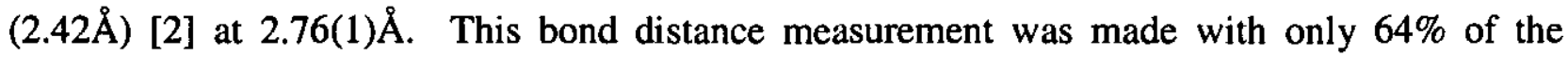
sodium ion sites occupied.[1] The deficiency of sodium arises from hydrolysis during washing, so that the actual formula was $\mathrm{Na}_{1.64} \mathrm{H}_{0.36} \mathrm{Ti}_{2} \mathrm{O}_{3}\left(\mathrm{SiO}_{4}\right) \cdot 1.8 \mathrm{H}_{2} \mathrm{O}$. Because of the deficiency of $\mathrm{Na}^{+}$, the sodium ion positions were found to be disordered with partial occupancy by water (or hydronium ions). It is possible to obtain the fully occupied sodium phase by not washing the product of the hydrothermal reaction with water or using $\mathrm{NaOH}$ to replace the protons.

Ion Exchange Properties. One of the principal interests in the sodium titanium silicate under discussion is its ability to remove $\mathrm{Cs}^{+}, \mathrm{Sr}^{2+}$ and actinides from highly basic nuclear waste solutions.[3] In fact, the X-ray structure work described here, very neatly explains the ion exchange behavior of this exchanger. Figure 4 presents the potentiometric titration curves for alkali metals on the titanium silicate exchanger.[4] The selectivity is clearly seen in acid solution as $\mathrm{K}^{+}>\mathrm{Cs}^{+} \gg>\mathrm{Na}^{+}>>\mathrm{Li}^{+}$. In fact, it turns out that the true sequence is $\mathrm{Cs}^{+}>\mathrm{Rb}^{+}>>\mathrm{K}^{+}>>\mathrm{Li}^{+}$, as shown by $\operatorname{logKc}$ versus uptake curves.[5] However, the situation is not that simple. There are 
three exchange sites in this titanosilicate, the framework site, the near framework site and the center tunnel site. To obtain thermodynamic selectivities, it is necessary to determine to which site the ion locates so as to be able to describe the phase involved. This site determination can only be revealed by X-ray structural studies, and this study has been partially carried out in the case of $\mathrm{Na}^{+}, \mathrm{K}^{+}$and $\mathrm{Cs}^{+}$. The very high selectivity for $\mathrm{Cs}^{+}$is explained by the fact that $\mathrm{Cs}^{+}$just fits in the center of the tunnel at $c=1 / 4,3 / 4$. The $\mathrm{Cs}^{+}$ion is bonded to eight framework oxygens as shown in Figure 5 at a distance of 3.183(5) $\AA$. This distance is very close to the sum of the ionic radii for $\mathrm{Cs}^{+}$and $\mathrm{O}^{2-}$. In fact, the selectivity sequence determined by ion exchange [5] is for the center tunnel site.

Titanium Silicate Pharmacosiderites. Pharmacosiderite is a mineral of composition $\mathrm{KFe}_{4}(\mathrm{OH})_{4}\left(\mathrm{AsO}_{4}\right)_{3}$ that has a framework structure with tunnels similar to those described above.[6] Chapman and Roe reported the synthesis of a titanium silicate analogue with a composition close to $\mathrm{K}_{3} \mathrm{H}(\mathrm{TiO})_{4}\left(\mathrm{SiO}_{4}\right)_{3} \cdot 4 \mathrm{H}_{2} \mathrm{O}$.[7] We prepared this compound as a highly crystalline solid and determined its structure from X-ray powder diffraction data.[8] The crystals are cubic with $a=7.7644(3) \AA$, space group $P \overline{4} 3 \mathrm{~m}$ and $Z=1$. The structure is similar to that of the previously described titanium silicate in that the $(\mathrm{TiO})_{4}$ cubane-like clusters exist in this compound also. The difference lies in the cubic nature of this compound that requires bridging of the $\mathrm{TiO}$ clusters by silicate groups in the c-axis direction as well as the a and $\mathrm{b}$ directions. This arrangement results in identical tunnels that are mutually perpendicular and parallel to the three unit cell directions. The $\mathrm{K}^{+}$ions reside exactly in the cube face centers and are 12 coordinate being bonded to eight silicon oxygens at 3.234(4) $\AA$ and four water molecules at 3.17(1) (Figure 6). According to Prewitt and Shannon [2], the radius for 12-coordinate $\mathrm{K}^{+}$is $1.60 \AA$ making the sum of the radii $3.0 \AA$, somewhat smaller than the observed bond values. 
WSRC-TR-2001-00583

Exchange of $\mathrm{Cs}^{+}$for $\mathrm{K}^{+}$was carried out by a titration procedure and the product structure determined by X-ray diffraction procedures for $\mathrm{K}_{3} \mathrm{H}(\mathrm{TiO})_{4}\left(\mathrm{SiO}_{4}\right)_{3} \cdot 4 \mathrm{H}_{2} \mathrm{O}$. [8] The positioning of $\mathrm{Cs}^{+}$ions is interesting. They locate in a disordered site at $1 / 21 / 21 / 2 \pm 0.0587$ or $\pm 0.459 \AA$ from the

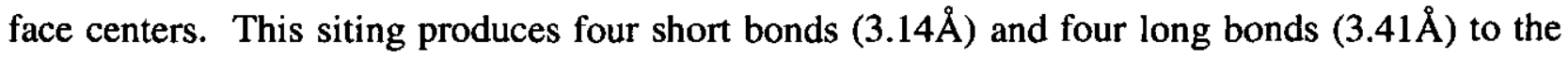
silicate oxygens and similarly two short $(2.82 \AA)$ and two long (3.62 $)$ bonds to the water molecules within the tunnels. One may wonder why the cesium ion did not locate at the face centers. According to the ionic radii provided by Prewitt and Shannon, $\mathrm{Cs}^{+}$in C.N. 12 has a radius of $1.88 \AA$. Therefore, the Cs-O bonds should be of the order of $3.24 \AA$ or very close to those exhibited by potassium in the face centers. Thus, it would appear that $\mathrm{Cs}^{+}$could fit in the face centers, but is more stable slightly outside this position.

Ion Exchange and Structure Modification. The alkali metal selectivity series for $\mathrm{K}_{3} \mathrm{H}(\mathrm{TiO})_{4}\left(\mathrm{SiO}_{4}\right)_{3} \cdot 4 \mathrm{H}_{2} \mathrm{O}$ is $\mathrm{Cs}^{+}>\mathrm{K}^{+}>\mathrm{Na}^{+}>\mathrm{Li}^{+}$.[8] The channel openings are not large enough to allow hydrated ions to diffuse into the tunnels. Thus, the ions must dehydrate to diffuse down the channels followed by water molecules to partially rehydrate the ions. Apparently, $\mathrm{Cs}^{+}$ion is just able to negotiate through the channel openings but may do so by repelling the oxygen atoms to a small extent. It occurred to us that if the $\mathrm{Cs}^{+}$resided within the face centers, it would have a more stable bonding environment, eight strong bonds to silicate oxygens instead of four and in addition four strong bonds to water molecules. For this to occur, it was felt that a slight expansion of the unit cell would allow for this siting. To accomplish the desired expansion, we replaced all or parts of the silicate by germanate groups, and indeed, the $\mathrm{K}_{\mathrm{d}}$ for $\mathrm{Cs}^{+}$increased from $\sim 10,000$ to $50,000 \mathrm{ml} / \mathrm{g}$. The titanium pharmacosiderite is even more selective for $\mathrm{Sr}^{2+}$ than for $\mathrm{Cs}^{+}$.[9] A comparable study to optimize the selectivity for $\mathrm{Sr}^{2+}$ has not been carried out nor 
WSRC-TR-2001-00583

has an X-ray mechanism been established. Strontium exchange in several waste systems will be presented at the end of this section.

Sodium Nonatitanate, $\mathrm{Na}_{4} \mathrm{Ti}_{2} \mathrm{O}_{20} \underline{n H}_{2} \mathrm{O}$. This compound was prepared by treatment of titanium hydroxide hydrothermally with different concentrations of $\mathrm{NaOH}$.[10] The product is semicrystalline with the degree of crystallinity varying with the strength of the $\mathrm{NaOH}$ solution and time and temperature of hydrothermal treatment. Because of the non-descript nature of this exchanger, only partial information on its structure is available. The compound is definitely layered, as the layers may be expanded by soaking in water. This is revealed by the shift of the first peak in the $\mathrm{X}$-ray pattern to higher d-spacings. The behavior of the solid as a $\mathrm{Sr}^{2+}$ sorber depends upon the structure with samples such as 67B and 64B (see Experimental Section), yielding extremely high $\mathrm{Kd}$ values and more crystalline samples such as $11 \mathrm{~B}$, yielding much lower $\mathrm{Kd}$ values. This compound has been highly effective in removing $\mathrm{Sr}^{2+}$ from a simulated Savannah River tank waste solution. A deeper look into structural aspects is required to understand this variation in selectivity.

Strontium Ion Exchange. In previous studies, we examined the $\mathrm{Sr}^{2+}$ sequestration and removal from several waste solutions at the Hanford site. The exchangers used and their designations follow[10]: (1) a highly crystalline sample of sodium titanium silicate, $\mathrm{Na}_{2} \mathrm{Ti}_{2} \mathrm{O}_{3}\left(\mathrm{SiO}_{4}\right) \cdot 2 \mathrm{H}_{2} \mathrm{O}$, with no $\mathrm{Nb}$ substitution [1,9] designated as NaTS; (2) a highly crystalline pharmacosiderite from which $\mathrm{K}^{+}$was removed by acid washing to yield $\mathrm{H}_{4}(\mathrm{TiO})_{4}\left(\mathrm{SiO}_{4}\right)_{3} \cdot 8 \mathrm{H}_{2} \mathrm{O}$ designated HTiSi; (3) a semi-crystalline pharmacosiderite made by the sol-gel method, $\mathrm{K}_{3} \mathrm{H}(\mathrm{TiO})_{4}\left(\mathrm{SiO}_{4}\right)_{3} \cdot 4 \mathrm{H}_{2} \mathrm{O}$ designated $\mathrm{KTiS}_{\text {sol; }}$ and (4) a sodium titanate with an interlayer spacing of $\sim 10 \AA$. The X-ray patterns of these exchangers are shown in Figure 7. These exchangers were tested for $\mathrm{Sr}^{2+}$ removal from several Hanford waste solution whose compositions are given in 
WSRC-TR-2001-00583

Table 1. "N-springs" is a ground water, while the remaining three are tank waste simulants. Although the NCAW and DSSF-7 indicate little or no $\mathrm{Sr}^{2+}$, we added $\mathrm{Sr}^{2+}$ to a level of $0.024 \mathrm{mg} / \mathrm{L}$. The 101SY-Cs5 contained significant amounts of $\mathrm{Sr}^{2+}$ complexants. The results are summarized in a series of Tables 2-5.

All of the exchanger samples proved satisfactory for removal of $\mathrm{Sr}^{2+}$ from the N-Springs simulant. This was particularly so for the V:m (volume to mass) ratio 1000:1. The poorest exchangers are the zeolites, which are normally used for mildly basic waste solutions. The sample with the highest affinity was the NaTS sample and the poorest was the pharmacosiderite, HTiSi. The low Kd value for this sample is probably the result of its high acid character. The sodium nonatitanate was also very selective, especially at the high V:m value. The same two exchangers, NaTS and NaTi performed very well with the NCAW and DSSF-7 simulants. All the exchangers performed poorly in the 101SY-Cs5 solution because they were unable to remove Sr from the complexants. We subsequently showed that addition of $\mathrm{Ca}^{2+}$ frees up the $\mathrm{Sr}^{2+}$ and then removal by NaTS proceeds smoothly.[11] For NaTi to remove ${ }^{90} \mathrm{Sr}$, one needs to use a cation other than $\mathrm{Ca}^{2+}$ such as non-radioactive strontium to free up sufficient ${ }^{90} \mathrm{Sr}$ for removal since the presence of excess added $\mathrm{Ca}^{2+}$ interfered with uptake of $\mathrm{Sr}^{2+}$ by $\mathrm{NaTi}$.

\section{Experimental Section}

Because the CST (NaTS) and $\mathrm{NaTi}$ samples showed the highest affinity for $\mathrm{Sr}^{2+}$, we initiated this study with these samples.

Synthesis of Sodium Titanates. Two general methods were used to prepare the sodium titanate. In both cases, titanium isopropoxide, $\mathrm{Ti}\left(\mathrm{i}-\mathrm{OC}_{3} \mathrm{H}_{7}\right)_{4}$, TiIP, was used as the source of titanium. 
WSRC-TR-2001-00583

Method I: A solution of TilP was prepared and added to a pre-determined concentration of $\mathrm{NaOH}$. After stirring for 15-30 minutes, the gel was transferred to a teflon-lined pressure vessel and heated at temperatures ranging from $150-200^{\circ} \mathrm{C}$ for different lengths of time.

Method II: In this method, the gel was refluxed in the $\mathrm{NaOH}$ solution before adding it to the pressure vessel.

Table 6 lists the conditions for several preparations and the type of X-ray diffraction patterns produced. The products group themselves into three structure types labeled T1, T2 and T3 in Table 6, based upon their X-ray diffraction patterns. The T1 types were obtained under mild conditions, low ratios of $\mathrm{Na}$ :Ti or if this ratio exceeds 4 , temperatures of $170^{\circ} \mathrm{C}$. These preparations are the least crystalline, but with a sharp initial diffraction peak. Higher mol ratios of $\mathrm{Na}: \mathrm{Ti}$ and temperatures of $190-200^{\circ} \mathrm{C}$ yield $\mathrm{T} 2$ type as marked on the X-ray patterns of Figures 8a and $\mathbf{8 b}$. These compounds are also poorly crystalline, but all the peaks are broad. Still higher $\mathrm{NaOH}: \mathrm{Ti}$ ratios and temperatures of $190-200^{\circ}$ yield the most crystalline products labeled T3.

Table 7 presents the analysis of $\mathrm{Na}$ and $\mathrm{Ti}$ for several of the samples. The theoretical Ti:Na mole ratio for $\mathrm{Na}_{4} \mathrm{Ti}_{9} \mathrm{O}_{20}$ is $1: 0.444$. We note that the sodium content is high for the first four samples. The reason for this imbalance was traced to the presence of $\mathrm{Na}_{2} \mathrm{CO}_{3}$, which showed up in the X-ray pattern for $23 \mathrm{~B}$ and the IR spectra. Those samples containing $\mathrm{Na}_{2} \mathrm{CO}_{3}$ exhibited bands at $\sim 1450$ and $1400 \mathrm{~cm}^{-1}$, indicative of the presence of $\mathrm{CO}_{3}{ }^{2-}$. Some $\mathrm{NaOH}$ may also be present. Initially, these samples were washed in methanol to prevent hydrolysis, but after washing in water, it is observed that the ratios approach the theoretical much more closely. However, the T3 sample, 23BW2 (W2 meaning it was washed with water twice), is still high in sodium content. Selectivities were determined as $K_{d}$ values where $K_{d}=\left(\frac{C_{i}-C_{e}}{C_{e}}\right) v / m, C_{i}, C_{e}$ are the 
WSRC-TR-2001-00583

initial and final solution concentrations for a given ion, $\mathrm{v} / \mathrm{m}$ is the solution volume to exchanger mass utilized.

Table 8 presents the $\mathrm{K}_{d}$ values for $\mathrm{Sr}^{2+}$ for several of the samples listed in Table 6. It is seen that the $\mathrm{T} 1$ samples have the lowest $K_{d}$ values, $T 2$ the highest, and the one T3 sample, a high $\mathrm{K}_{\mathrm{d}}$ value. This latter value may be influenced by the high $\mathrm{Na}_{2} \mathrm{CO}_{3}$ content of $23 \mathrm{~B}$. This sample was submitted to SR for testing because of its high $\mathrm{K}_{\mathrm{d}}$ value, but would need further examination as the washed sample gave a $\mathrm{K}_{\mathrm{d}}$ value of $\sim 40,000 \mathrm{ml} / \mathrm{g}$. Examples of actual sample preparations follow.

Preparation of $\mathrm{Na}_{4} \mathrm{Ti}_{2} \mathrm{O}_{20}$ (Sample 23B). $15.1 \mathrm{~g}$ of titanium isopropoxide (Aldrich 97\%, $d=0.9711) \mathrm{Ti}\left(\mathrm{OC}_{3} \mathrm{H}_{7}\right)_{4}(51.5 \mathrm{mmol})$ was added to a plastic beaker, followed by addition of $43.0 \mathrm{~g}$ of a 50 wt $\% \mathrm{NaOH}$ solution $(537 \mathrm{mmol} \mathrm{NaOH})$. The mixture was stirred vigorously during the addition and for 15-20 minutes after the addition was complete. The mixture was then transferred to a teflon-lined pressure vessel with $12 \mathrm{ml}$ of distilled, deionized water (ddi). The vessel was placed inside a preheated oven at $190^{\circ} \mathrm{C}$ and allowed to cook for 22 hours. The bomb was cooled rapidly in cold water, the solid recovered by filtration and washed five times with ethanol and air-dried. Centrifugation may be required to separate the solid from the liquid in the latter washings, yield $6.05 \mathrm{~g}$, essentially quantitative: found: $\mathrm{Na}, 16.16 \% ; \mathrm{Ti}, 37.82 \%$; $\mathrm{Ti}: \mathrm{Na}=$ 1:0.89, theoretical ratio $9 / 4=0.444$. The high sodium level is due to incomplete removal of $\mathrm{NaOH}$ and sodium carbonate. Washing with water (see Table 7) removed most, but not all of the excess sodium. More thorough water washing of the nonatitanates is required.

A second preparation (64B) represents a variation in the procedure in that the gel was preheated before being subjected to hydrothermal treatment. $9.1 \mathrm{~g}(32 \mathrm{mmol})$ titanium isoproxide was added to a solution of $50 \mathrm{wt} \% \mathrm{NaOH}(22.2 \mathrm{~g})$ slowly with stirring. Then $10 \mathrm{ml}$ of ddi $\mathrm{H}_{2} \mathrm{O}$ 
was added and stirring continued. The mixture was then refluxed in a plastic round bottom flask, fitted with a condenser. Refluxing was continued for 3.4 hours. The refluxed mixture was then transferred to a teflon-lined pressure vessel using two $8 \mathrm{ml}$ portions of ddi ( $80 \mathrm{ml}$ capacity) and heated at $193 \pm 3^{\circ} \mathrm{C}$ for 20 hours. The product was washed as before, but this time with a $50-50$ mixture of water and alcohol. The air-dried sample gave $9.55 \% \mathrm{Na}, 39.70 \% \mathrm{Ti}$; ratio $\mathrm{Ti}: \mathrm{Na}=$ 1:0.501. This sample is very much closer to the theoretical stoichiometry than $23 \mathrm{~B}$. We note that most of the samples in Table 6 were prepared by the reflux method.

The deviation of the stoichiometry is very serious in the case of sample 23B and much less so for sample 64B. The excess $\mathrm{Na}$ was traced to the presence of $\mathrm{Na}_{2} \mathrm{CO}_{3}$ and $\mathrm{NaOH}$. There was much less excess $\mathrm{Na}$ in 64B because of the mixed water-alcohol wash used. The reason for avoiding the use of water was to prevent hydrolysis, which incorporated protons in place of $\mathrm{Na}^{+}$. In actual use in highly basic solutions, $\mathrm{Na}^{+}$would replace the $\mathrm{H}^{+}$in the sodium nonatitanate resulting from hydrolysis. The IR spectra showed the presence of carbonate ion in 23B by the bands at 1450 and $1400 \mathrm{~cm}^{-1}$ and sodium carbonate was also present in the X-ray powder pattern (XRPD). A water wash removed the major portion of $\mathrm{Na}_{2} \mathrm{CO}_{3}$ as evidenced by the absence of the carbonate bands in the IR spectrum and diffraction peaks in the XRPD. Therefore, it is recommended that thorough water washing is in order, as the presence of $\mathrm{H}^{+}$due to hydrolysis would do no harm, when used in strongly basic media.

Ion Exchange Behavior. The $\mathrm{K}_{\mathrm{d}}$ values for the two samples submitted for testing to

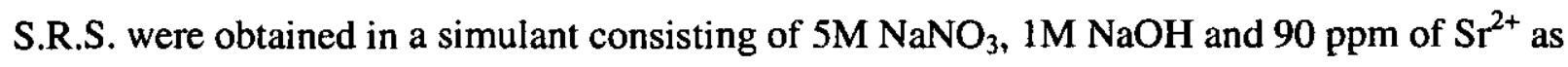


WSRC-TR-2001-00583

$\mathrm{Sr}\left(\mathrm{NO}_{3}\right)_{2}$ and traced with ${ }^{89} \mathrm{Sr}$. The results are given below. The $\mathrm{V} / \mathrm{m}=200$.

\begin{tabular}{|c|c|}
\hline Sample No. & $\underline{K}_{d} \underline{S r}(\mathrm{ml} / \mathrm{g})$ \\
\hline 23B & 40,000 \\
\hline 64B & $>131,000$ \\
\hline $23 \mathrm{BW} *$ & $>131,000$ \\
\hline 64BW & $>134,000$ \\
\hline
\end{tabular}

These results show that the presence of $\mathrm{Na}_{2} \mathrm{CO}_{3}$ and/or $\mathrm{NaOH}$ lower the $\mathrm{K}_{\mathrm{d}}$ values of sodium nonatitanate. From the analytical data, it is estimated about four additional moles of sodium were present in the unwashed sample of 23B. Even accounting for this mass as lowering the amount of nonatitanate present, the $\mathrm{K}_{\mathrm{d}}$ is still lower than for $64 \mathrm{~B}$. If all the excess $\mathrm{Na}^{+}$was present as $\mathrm{NaOH}$, it would constitute an increase in mass of $160 \mathrm{~g}$ for $1023 \mathrm{~g}$ of $\mathrm{Na}_{4} \mathrm{Ti}_{9} \mathrm{O}_{20} \cdot 10 \mathrm{H}_{2} \mathrm{O}$ or $13.5 \%$. This would increase the $\mathrm{K}_{\mathrm{d}}$ to $46,240 \mathrm{ml} / \mathrm{g}$, i.e., $40,000 / .865$. Similarly for $\mathrm{Na}_{2} \mathrm{CO}_{3}$, the $\mathrm{K}_{\mathrm{d}}$ would increase to $48,000 \mathrm{ml} / \mathrm{g}$. Removal of the $\mathrm{Na}_{2} \mathrm{CO}_{3}+\mathrm{NaOH}$ in the washing resulted in a much larger $\mathrm{K}_{\mathrm{d}}$ as shown in the above table.

Sodium Titanium Silicate, $\mathrm{Na}_{2} \mathrm{Ti}_{2} \mathrm{O}_{3} \mathrm{SiO}_{4}{ }_{4}^{2} \mathrm{H}_{2} \mathrm{O}, \mathrm{CST}$. We realized from earlier work that the titanosilicate could be prepared in semi-crystalline as well as crystalline form. Our objective was to obtain a product optimized for $\mathrm{Sr}^{2+}$ uptake, rather than $\mathrm{Cs}^{+}$selectivity. Furthermore, we felt that a less crystalline solid would be more effective in the removal of actinides since they may be present as anions. As a result, it was less likely that they would exchange $\mathrm{Na}^{+}$in narrow tunnels, but might still be adsorbed onto the surface of a poorly crystalline product. 
WSRC-TR-2001-00583

Two preparative methods were utilized. One using $\mathrm{TiCl}_{4}$ as the source of $\mathrm{Ti}$ and the second, titanium tetra isopropoxide, $\mathrm{Ti}\left(\mathrm{O}_{3} \mathrm{C}_{3} \mathrm{H}_{7}\right)_{4}$. We varied time, temperature and concentration.

In our first series of sample preparations, we examined the effect of time on crystallinity and resultant affinity for $\mathrm{Sr}^{2+}$. The preparations utilized titanium isopropoxide and were heated at $180^{\circ} \mathrm{C}$ for different lengths of time from 1 h to $7 \mathrm{~d}$. The ratio of ingredients $\mathrm{Ti}: \mathrm{Si}: \mathrm{NaOH}$ was 1:2:12.8. The results are shown in Table 9. The $K_{d}$ values were determined at $\mathrm{V} / \mathrm{m}=250$ and spiked with ${ }^{89} \mathrm{Sr}$. The values in the first $\mathrm{K}_{\mathrm{d}}$ column indicate an increasing selectivity for $\mathrm{Sr}^{2+}$ as the crystallinity increases. The only exception is the sample obtained after $1 \mathrm{~h}$. This sample had an initial d-spacing of $9.70 \AA$ (Figure 9A). The titanosilicate has an initial d-spacing of $7.90 \AA$ and this peak first appears in the 10h sample (Figure 9B). Thus, the phase obtained in one hour is not CST, but a precursor of unknown structure. The product obtained in $10 \mathrm{~h}$ is a mixture of the unknown phase and CST. This accounts for the variation in $K_{d}$ values.

When the concentration of the supporting electrolytes is increased 100-fold, the $K_{d}$ values decrease, but now we clearly see that the $K_{d}$ values increased with increase in crystallinity (Table 9, last column).

An important factor is the concentration of $\mathrm{NaOH}$ in the final mix of ingredients. Above a concentration of $2.5 \mathrm{M}$, a major impurity of composition $\mathrm{Na}_{2} \mathrm{TiOSiO}_{4}$ (See PDF No. 181261) is obtained as shown in Figure 10. It is easily identified by the peaks at $5.1 \AA$ and $2.74 \AA$ mixed with the CST. This phase has no ion exchange ability, and therefore, is inert and would add to the bulk solid waste. Another important factor is that the silica needs to be present in excess in the reactant mix. For example, we note that the mole ratio of $\mathrm{Ti}$ to $\mathrm{Si}$ is $1: 2$ in this preparation, but the ratio in CST is 2:1. Ratios of Ti:Si as low as 1:1 have been used with good results. 
Temperatures have been varied from $170^{\circ}$ to $210^{\circ} \mathrm{C}$ with higher crystallinity obtained at the higher temperatures. However, the factors as to $\mathrm{NaOH}$ concentration, ratio of ingredients and temperature are all correlated and need to be adjusted experimentally. Two preparations, one for a highly crystalline sample and another semi-crystalline, are given at the end of this section.

While we have seen that the $K_{d}$ values increase with increased crystallinity, we intuitively felt that the highly crystalline product might exhibit slow kinetics. Therefore, we carried out kinetic experiments on a highly crystalline CST DMI-13-2 and a semi-crystalline sample DMI13-1. The results are shown in Figure 11. It is seen that the $K_{d}$ values for the crystalline sample are much lower as a function of time than the semi-crystalline sample. However, the uptake of $\mathrm{Sr}^{2+}$ after $2 \mathrm{~h}$ of equilibration for the crystalline sample is about $91 \%$ or close to the initial measured value of sample $13-1$ at 2 min. time. Based on these results, we decided to submit a sample for testing at SRTC similar to DMI-13-1, i.e., DMI-11-1. This sample preparation is described below and its performance in $\mathrm{Sr}^{2+}$ uptake is shown in Figure 12. The increase in $\mathrm{K}_{\mathrm{d}}$ and uptake with time is very close to that of DMI-13-1, but the curve extends over a much longer time period.

Preparation of Sodium Titanium Silicate, sample DMI-11-1. We prepared a sample of sodium titanium silicate (CST) that showed a high selectivity for $\mathrm{Sr}^{2+}$ uptake. Reagants: $32.08 \mathrm{ml}$ of Ti( $\left(\mathrm{OC}_{3} \mathrm{H}_{7}\right)_{4}$ (Alfa Aesar, 97\%, density = 0.971); 16.58g Silicic Acid (Fisher Chem., 99.7\% $\mathrm{SiO}_{2}$ as determined by TGA), $51 \mathrm{ml}, 10 \mathrm{M} \mathrm{NaOH}$ solution. The $\mathrm{SiO}_{2}$ was dissolved in $30 \mathrm{ml}$ of the sodium $\mathrm{NaOH}$ followed by addition of the $\mathrm{Ti}\left(\mathrm{OC}_{3} \mathrm{H}_{7}\right)_{4}$ with continuous stirring. To this mixture was added the remainder of the sodium hydroxide, followed by $162 \mathrm{ml}$ of ddi $\mathrm{H}_{2} \mathrm{O}$. This mixture was added to a teflon-lined pressure vessel and heated at $180^{\circ} \mathrm{C}$ for 3.5 days. The solid was recovered by filtration, washed with dilute sodium chloride solution to prevent hydrolysis and 
finally washed twice with a minimum of water. The ratio of $\mathrm{Si}$ to $\mathrm{Ti}$ in the reaction mix was $2.50: 1$ and the concentration of the diluted reaction solution was $\mathrm{Ti}, 0.435 ; \mathrm{Si}, 1.12 \mathrm{M} ; \mathrm{NaOH}$, 2.09M. An X-ray diffraction pattern of the solid phase is shown in Figure 13, where it is seen to be poorly crystalline. Weight loss to $500^{\circ} \mathrm{C}$ measured $20.5 \%$. This is equivalent to a formula of $\mathrm{Na}_{1.6} \mathrm{H}_{0.4} \mathrm{Ti}_{2} \mathrm{O}_{3} \mathrm{SiO}_{4} \cdot 3.6 \mathrm{H}_{2} \mathrm{O}$. The highly crystalline samples contain $2 \mathrm{H}_{2} \mathrm{O}$ indicating a higher absorption of water in the semi-crystalline products.

Preparation of CST from $\mathrm{TiCl}_{4}$. To $30 \mathrm{ml}$ of a freshly prepared $2 \mathrm{M} \mathrm{TiCl}_{4}$ solution $\left(\mathrm{TiCl}_{4}\right.$ Aldrich) was added $40 \mathrm{ml}$ of a $30 \mathrm{wt} \% \mathrm{H}_{2} \mathrm{O}_{2}$ solution, $150 \mathrm{ml}$ of ddi and $40 \mathrm{ml}$ of $\mathrm{NaOH}(10 \mathrm{M})$. The peroxide forms a soluble complex with $\mathrm{Ti}$ that does not precipitate in $\mathrm{NaOH}$. Then $4.3 \mathrm{~g}$ silicic acid (Aldrich, 99.9\%) was dissolved in $200 \mathrm{ml}$ of $1 \mathrm{M} \mathrm{NaOH}$ and added dropwise with stirring to the reaction mixture. The mix was transferred to a $1 \mathrm{~L}$ teflon-lined pressure vessel and heated at $200^{\circ} \mathrm{C}$ for 10 days. This procedure leads to a highly crystalline product. Filtration and extensive water washing results in partial replacement of $\mathrm{Na}^{+}$by $\mathrm{H}^{+}$to yield a product, $\mathrm{Na}_{1.6}$ ${ }_{1.7} \mathrm{H}_{0.3-0.4} \mathrm{Ti}_{2} \mathrm{O}_{3} \mathrm{SiO}_{4} \cdot 1.8 \mathrm{H}_{2} \mathrm{O}$.

Pharmacosiderites. Because the time for carrying out tests on our samples at S.R., before the expiration of our grant period, was short we did not have time to optimize the samples of pharmacosiderite to be submitted. We, therefore, merely duplicated syntheses we had carried out earlier that exhibited high $\mathrm{K}_{d}$ values for strontium. These are described in what follows.

Synthesis of pharmacosiderite, sample EAB-LI-23. Reagents: fumed $\mathrm{SiO}_{2}$ (Sigma, 99.8\%); titanium tetraisopropoxide (Aldrich, 97\%); $\mathrm{KOH}$ (Fisher, 5.055M). $20.02 \mathrm{~g}$ fumed $\mathrm{SiO}_{2}$ $(0.322 \mathrm{M})$ was added to $170 \mathrm{ml}$ of ddi $\mathrm{H}_{2} \mathrm{O}$ in a plastic beaker with stirring, followed by addition of $45.75 \mathrm{~g}(0.161 \mathrm{M})$ of the titanium isopropoxide. The resultant gel was stirred for 6 hours. The mol ratio of reactants $\mathrm{Si}: \mathrm{Ti}: \mathrm{H}_{2} \mathrm{O}$ was $2: 1: 58.6$. The gel was centrifuged and the supernatent 
WSRC-TR-2001-00583

liquid poured off. The gel was then washed twice by centrifugation and then transferred to a 500 ml plastic beaker using $115.2 \mathrm{~g}$ ddi $\mathrm{H}_{2} \mathrm{O}$. To this gel was added $70.5 \mathrm{~g}(57.8 \mathrm{ml})$ of the $\mathrm{KOH}$ solution with constant stirring. The mol ratio of reactants was Ti:Si: $\mathrm{KOH}: \mathrm{H}_{2} \mathrm{O}, 1: 2: 1.8: 58.3$. The mixture was then added to a $1 \mathrm{~L}$ teflon-lined pressure vessel and heated at $200^{\circ} \mathrm{C}$ for 47 hours. The pressure vessel was quenched in cold water and when cooled, the solid was filtered, using $0.2 \mu \mathrm{FP}$ membrane. It was washed with absolute ethanol and dried in an oven at $55^{\circ} \mathrm{C}$. The X-ray diffraction pattern is shown in Figure 14. Yield was $28.3 \mathrm{~g}(97.2 \%)$ based on the formula $\mathrm{K}_{3} \mathrm{H}(\mathrm{TiO})_{4}\left(\mathrm{SiO}_{4}\right)_{3} \cdot 4 \mathrm{H}_{2} \mathrm{O}$.

Preparation of $\mathrm{Na}_{3} \mathrm{H}(\mathrm{TiO})_{4}\left(\mathrm{SiO}_{4}\right)_{3} \cdot 4 \mathrm{H}_{2} \mathrm{O}$. A new preparation of $\mathrm{K}_{3} \mathrm{H}(\mathrm{TiO})_{4}\left(\mathrm{SiO}_{4}\right)_{3} \cdot 4 \mathrm{H}_{2} \mathrm{O}$ was carried out as before, but at a level of $40 \%$ of the reagents used for EAB-23. The yield was $9.26 \mathrm{~g}$ or $82 \%$ conversion to the sodium phase. Sodium tetraphenylborate, $\mathrm{NaB}\left(\mathrm{C}_{6} \mathrm{H}_{5}\right)_{4}$, was utilized to substitute $\mathrm{Na}^{+}$for $\mathrm{K}^{+}$. A mixed solution of $0.2 \mathrm{M}$ in $\mathrm{NaB}\left(\mathrm{C}_{6} \mathrm{H}_{5}\right)_{4}, \mathrm{Na}-\mathrm{TPB}$, (Aldrich, 99.5\%) $1.0 \mathrm{M}$ in $\mathrm{NaCl}$ and $0.01 \mathrm{M}$ in EDTA (Fisher Chem.) was prepared by adding $6.84 \mathrm{~g} \mathrm{Na}$ TPB, $5.846 \mathrm{~g} \mathrm{NaCl}$ and $0.305 \mathrm{~g}$ EDTA to $100 \mathrm{ml}$ ddi $\mathrm{H}_{2} \mathrm{O}$. To this mixture was added $3.526 \mathrm{~g}$ of $\mathrm{K}_{3} \mathrm{H}(\mathrm{TIO})_{4}\left(\mathrm{SiO}_{4}\right)_{3} \cdot 4 \mathrm{H}_{2} \mathrm{O}$ prepared previously. A yellow precipitate was observed to form. The mixture was shaken for one hour, then centrifuged and the supernatant decanted. The solid was then extracted with three $50 \mathrm{ml}$ portions of acetone to remove the K-TPB. The sodium phase was then treated with $40 \mathrm{ml}$ of $2 \mathrm{M} \mathrm{HNO}_{3}$ to remove the $\mathrm{Na}^{+}$followed by a second treatment with $30 \mathrm{ml}$ of $2 \mathrm{M} \mathrm{HNO}_{3}$. This treatment ensured the complete removal of $\mathrm{K}^{+}$. Two grams of the proton phase was converted to the sodium phase by treatment with $15 \mathrm{ml}$ of $0.1 \mathrm{M} \mathrm{NaOH}+0.1 \mathrm{M}$ $\mathrm{NaNO}_{3}$. The final $\mathrm{pH}$ was 6.7 , indicating some protons may still be present. Therefore, a second treatment with $15 \mathrm{ml}$ of $\mathrm{NaOH}$ was carried out and the excess $\mathrm{NaOH}$ washed out with $15 \mathrm{ml} \mathrm{H}_{2} \mathrm{O}$. This sample is TAMU DMI-25. 
WSRC-TR-2001-00583

\section{Test Results}

Derived at the Savannah River Technology Center [12,13]. In addition to the samples described here, several other types of samples, as enumerated below were examined by WSRC.

1. Amorphous monosodium titanates; MST \#33180, run at different time periods, MST 33470, MST \#TNX.

2. SrTreat - A version of the monosodium titanate prepared by Fortnum Engineering in Finland; SrTreat \#48, \#49, \#8.

3. Sodium nonatitanate (ST), two samples from Honeywell, ST-39287-5A and ST-392875B and two samples from Texas A\&M University RC-4-23B and RC-4-64B.

4. Sodium titanium silicate, ideal formula $\mathrm{Na}_{2} \mathrm{Ti}_{2} \mathrm{O}_{3}\left(\mathrm{SiO}_{4}\right) \cdot 2 \mathrm{H}_{2} \mathrm{O}$. Two crystalline commercially available phases CST-IE-910 and CST-IE-911 were obtained from UOP and a semi-crystalline sample optimized for $\mathrm{Sr}^{2+}$ removal, TAMU DMI-11-1 from Texas A\&M University.

5. Pharmacosiderites: TAMU EAB-II-23 is a potassium ion phase of composition $\mathrm{K}_{3} \mathrm{H}(\mathrm{TiO})_{4}\left(\mathrm{SiO}_{4}\right)_{3} \cdot 4 \mathrm{H}_{2} \mathrm{O}$ and DMI-25 a semicrystalline sample of composition $\mathrm{Na}_{3} \mathrm{H}(\mathrm{TiO})_{4}\left(\mathrm{SiO}_{4}\right)_{3} \cdot 4 \mathrm{H}_{2} \mathrm{O}$.

Sample performance. Sample performance is judged on the basis of two criteria, the Decontamination Factor (DF) or the distribution coefficient, $K_{d}$, which is an indication of removal capacity, and the kinetic factor, which is best revealed by graphs of total $\mathrm{Sr}^{2+}$ remaining in solution as a function of time. Data were obtained not only for uptake of strontium, but also of plutonium, uranium and neptunium. (see Figures 15 and 16 for solution compositions.)

A. Decontamination Factors, Table 10. For Sr removal - The MST sample, labeled MST-33180, exhibited DF values of greater than 100 in a $24 \mathrm{~h}$ time period in three of four 
different trials. Two other samples of MST performed less well than MST-33180. The variability of the MST samples may reflect differences in preparation or in post-preparation treatment, which could include sodium content, degree of hydration or aging.

SrTreat. Two samples of SrTreat \#49 and \#8 exhibited high DF values and one, \#48, much lower DFs. Since this material is a form of monosodium titanate, the same comments apply as for the MST samples.

The behavior of the nonatitanate samples can be explained on the basis of the factors described in this study. Sample 64B gave a T2 X-ray diffraction pattern and contained no, or very little, excess $\mathrm{Na}_{2} \mathrm{CO}_{3}$. It performed extremely well for $\mathrm{Sr}^{2+}$ uptake. Sample 23B exhibited a T3 X-ray diffraction pattern, indicating a higher degree of crystallinity and an excess of Na, yet it performed better than many of the tested samples. The samples submitted by Honeywell were not as good, but we do not have X-ray patterns for comparison. However, sample 5B performed better than most other samples for $\mathrm{Sr}^{2+}$ uptake as shown in Figure 15.

A surprise is the evident failure of the CST samples to rank in the highest levels. The Texas A\&M product was the best of the CST samples, but even it is not nearly as effective as the titanates. The pharmacosiderites produced interesting results. The $\mathrm{K}^{+}$phase was moderately effective in $\mathrm{Sr}$ uptake, but the sodium phase was much better. What is notable is that this potassives phase sample, DMI-1-25, had the highest DF for Pu uptake, 247. As detailed in the introduction, the $\mathrm{K}^{+}$pharmacosiderite is cubic with $\mathrm{K}^{+}$in the face centers (see Figure 6). Sodium ion being much smaller than $\mathrm{K}^{+}$would not be tightly held in the face centers. The positioning of $\mathrm{Na}^{+}$in the lattice is not known, but it is less strongly held than $\mathrm{K}^{+}$. Another factor to consider is the fact that the sodium phase was somewhat less crystalline than the $\mathrm{K}^{+}$phase. 
Actinide Removal. (a) Plutonium. TAMU sample DMI-25 exhibited, by far, the highest $\mathrm{K}_{\mathrm{d}}$ and $\mathrm{DF}$ for Pu after $7 \mathrm{~d}$ equilibration. However, the $24 \mathrm{~h}$ values were quite low. SrTreat \#8 showed the same type of behavior, a very low DF at the $24 \mathrm{~h}$ point, but a much higher one after 7d. The other SrTreat samples exhibited among the lowest DF values. Three sodium nonatitanate samples exhibited relatively high $\mathrm{DF}$ values for $\mathrm{Pu}$ after $24 \mathrm{~h}$ with considerable increase in DF over the $7 \mathrm{~d}$ period. Only sample 23B did not conform to this behavior and yielded low DF values for Pu. This may stem from the increased crystallinity of this compound. For the monosodium titanate, only some trials with sample MST\#33180 gave reasonable DF values, but generally lower than those for the nonatitanates. (b) Uranium. None of the sorbent exhibited respectable values of DF or Kd for uranium. This may stem from the fact that uranium is present in the waste simulants at a much higher level than the other actinides. Still, it should be noted that several thousand $\mathrm{ppb}$ of $\mathrm{U}$ were sorbed. Interestingly, the sodium pharmacosiderite did sorb more than two-thirds of the uranium [13]. The double precipitation method, suggested below, may reduce the $\mathrm{U}$ level even further. (c) Neptunium. None of the samples gave particularly high DF or $K_{d}$ values. The sodium pharmacosiderite had the highest $7 d$ DF at 20.9 and had the highest uptake after the $7 \mathrm{~d}$ equilibration [13]. Relatively speaking, this value is quite good. Several other samples had values between 10 and 20 [three nonatitanates, one trial of MST\#33180 and SrTreat\#8].

\section{Kinetics of Exchange}

The rates of uptake of $\mathrm{Sr}^{2+}$ and the actinides in simulants approximating the composition of the S.R. wastes were carried out by WSRC $[12,13]$. Some of the results are reproduced in Figures 15 and 16. 
WSRC-TR-2001-00583

Strontium Uptake. Figure 15 is a summary of some of the results for $\mathrm{Sr}^{2+}$ uptake. At the 24h level of equilibration, three samples, ST-RC-4-64B, SrTreat \#8 and ST-RC-4-23B, fell below the $1 \mathrm{ppb}$ level. At the $7 \mathrm{~d}(168 \mathrm{~h})$ point, the samples below $1 \mathrm{ppb}$ remaining in solution were in the order 64B $>$ SrTreat $\# 8>5 B>23 B$. All other samples were between 1 and $8 \mathrm{ppb}$. The nonatitanate 64B consistently outpaced the other samples and at the $2 \mathrm{~h}$ equilibration point, had sorbed all but $1 \mathrm{ppb}$ of $\mathrm{Sr}^{2+}$. It should be noted that five other samples were below the 10ppb level at the $2 \mathrm{~h}$ point. Therefore, the major portion of time, $166 \mathrm{~h}$, is utilized to sorb $1-8 \mathrm{ppb}$. It is surprising that the CST samples did not perform well.

Actinides. (a) Plutonium - Figure 16A shows that the nonatitanates 64B and 5B achieved the highest Pu uptake, but that the fastest rate, up to the $24 \mathrm{~h}$ equilibration time, was achieved by 5B. The MST 33180 sample was somewhat slower, and also exhibited a slightly lower capacity. In a subsequent additional test [13], in which sample 5B was not included, the potassium pharmacosiderite EAB-II- 23 exhibited the fastest rate for $24 \mathrm{~h}$ and achieved a level of uptake of close to $99 \%$. The sodium pharmacosiderite was initially much slower, but eventually achieved the highest uptake, closely followed by SrTreat \#8 and the K-pharmacosiderite and then 64B and MST. It is quite possible that the potassium pharmacosiderite exhibited initial fast kinetics by forming an insoluble potassium plutonium hydroxide with the $\mathrm{K}^{+}$on the surface of the sorbent. If this is the case, then a higher surface area sample should exhibit faster kinetics.

(b) Uranium. This element is present in much higher levels, $12,000-14,000 \mathrm{ppb}$ than the other actinides. There is an initial rapid uptake of perhaps $4,000 \mathrm{ppb}$ by MST 33180 and EAB-II-23 in less than an hour [Ref. 13, Figure 4.4.3]. However, the rate of uptake of 64B surpasses that of the MST sample, while the sodium pharmacosiderite, DMI-25, equals it at the $24 \mathrm{~h}$ point. Sample 64B has taken up $\sim 6,000 \mathrm{ppb}$, MST somewhat less and the sodium pharmacosiderite 
(DMI-25) about 5,000 ppb. After 168h, TAMU DMI-25 has taken up slightly more than 10,000 ppb of U, sample 64B $\sim 9,000 \mathrm{ppb}$ and SrTreat \#8, about 8,000 ppb followed by MST at $\sim 7,000$ ppb. In an earlier test [12, Figure 8], other nonatitanates $5 A$ and $5 B$, as well as $64 B$, were shown to sorb $\sim 9,000 \mathrm{ppb} \mathrm{U}$ after $168 \mathrm{~h}$ equilibration.

(c) Neptunium. In an early test, MST 33180 outperformed two SrTreat samples \#48, \#49 and the CST 910, 911 samples [12, Figure 9]. Comparison of this MST sample with the nonatitanates is shown in Figure 16B. Two samples, ST-39287-5A and 5B exhibited rates equivalent to that of the MST, but ST-RC-64B was somewhat slower. However, at the $168 \mathrm{~h}$ time, all three of the nonatitanate samples had achieved the same Np uptake as had the MST.

In the latest series of tests with $\sim 600 \mathrm{ppb} \mathrm{Np}$, which included many more samples [13, Figure 4.4.4], the fastest rates (to the first 24h) were exhibited by RC-4-23B, RC-4-64B and MST 33180. However, the order of loading at the highest equilibration time (168h) was the sodium pharmacosiderite TAMU-DMI-25 (580 ppb) followed by SrTreat \#8 (555 ppb), TAMURC-4-64B (540 ppb), MST 33180 (520 ppb) and TAMU-RC-4-23B (500 ppb). The fact that the sodium pharmacosiderite sample DMI-25 achieved the highest uptake of U, Pu and Np over the 7d equilibration in competition with the MST and nonatitanate sample indicates that further work with this material is desirable.

\section{Conclusions}

1. The results indicate that a combination of monosodium titanate such as MST-33180 and a nonatitanate such as $5 \mathrm{~B}$ and/or 64B would effectively achieve acceptable levels of radioactive species containment. Standardized products of both types of exchangers need to be developed so as to avoid variability in performance. 
2. Sodium titanium pharmacosiderite should also receive additional study as it shows promise of being effective in strontium removal as well as high levels of actinide uptake.

3. Because the bulk of the radioactive species are taken up within a 2-hour time period, it would appear prudent to develop a process utilizing this behavior. A possible strategy would be to use smaller batches of waste, filter or centrifuge after 2-3 hours, and add a second portion of sorbent for perhaps a 3-4 hour hold and filter. The amount of sorbent used can be adjusted to be no more than would be used for a single in-tank $7 \mathrm{~d}$ procedure. The time saved by taking advantage of kinetic factors would allow the processing of far more waste than achievable in longer hold times.

4. The nonatitanate has been scaled up to the $5 \mathrm{~kg}$ level by Honeywell and could be made available commercially.

5. CST performed poorly, as did most of the SrTreat samples. However, the latest SrTreat sample \#8 did perform well. Fortum Oy should be able to determine why this sample performed well, whereas the earlier samples did not. If consistency in preparation is achieved, further study is warranted.

6. In summary, these screening tests indicate that sodium nonatitanates and the pharmacosiderites exhibit as good, or better a performance than MST. Therefore, somewhat larger scale tests are in order with these materials and perhaps including SrTreat and sodium pharmacosiderite. 
WSRC-TR-2001-00583

\section{References}

[1] Poojary, D.M.; Cahill, R.A.; Clearfield, A. Synthesis, Crystal Structures and Ion Exchange Properties of a Novel Porous Titanosilicate, Chemistry of Materials. 6, 2364 (1994).

[2] Prewitt, C.T. and Shannon, R.D. Use of Radii as an Aid to Understanding the Crystal Chemistry of High Pressure Phases, Transactions of the American Crystallographic Association 5, 57 (1969).

[3] Dosch, R.G.; Brown, N.E.; Stephens, H.P. and Anthony, R.G. Treatement of Liquid Nuclear Wastes with Advanced Forms of Titanate Ion Exchangers, Waste Management 93, 1751, Tucson, Arizona.

[4] Poojary, D.M.; Bortun, A.I.; Bortun, L.N. and Clearfield, A. Structural Studies on the Ion-Exchanged Phases of a Porous Titanosilicate, $\mathrm{Na}_{2} \mathrm{Ti}_{2} \mathrm{O}_{3} \mathrm{SiO}_{4} \bullet 2 \mathrm{H}_{2} \mathrm{O}$, Inorganic Chemistry 35, 6131-6139 (1996).

[5] (a) Bortun, A.I.; Bortun, L.N. and Clearfield, A. Ion Exchange Properties of a Cesium Ion Selective Titanosilicate, Solvent Extraction and Ion Exchange, 14, 341-354 (1996). (b) Clearfield, A.; Bortun, L.N. and Bortun, A.I. Alkali Metal Ion Exchange by the Framework Titanium Silicate $\mathrm{M}_{2} \mathrm{Ti}_{2} \mathrm{O}_{3} \mathrm{SiO}_{4} n \mathrm{H}_{2} \mathrm{O}(\mathrm{M}=\mathrm{H}, \mathrm{Na})$, Reactive Polymers, 43, 85-95 (2000).

[6] Buerger, M.J.; Dollase, W.A. and Garaycocher-Wittke, I. The Structure and Composition of the Mineral Pharmacosiderite, Kristallography 125, 92 (1967).

[7] Chapman, D.M. and Roe, A.L. Synthesis, Characterization and Chemistry of Microporous Titanium-Silicate Materials, Zeolites 10, 730 (1990).

[8] Behrens, E.A.; Poojary, D.M. and Clearfield, A. Synthesis, Crystal Structures, and Ion-Exchange Properties of Porous Titanosilicates, $\mathrm{HM}_{3} \mathrm{Ti}_{4} \mathrm{O}_{4}\left(\mathrm{SiO}_{4}\right)_{3} \bullet 4 \mathrm{H}_{2} \mathrm{O}$ $\left(\mathrm{M}=\mathrm{H}^{+}, \mathrm{K}^{+}, \mathrm{Cs}^{+}\right)$, Structural Analogues of the Mineral Pharmacosiderite, Chemistry of Materials, 8, 1236-1244 (1996).

[9] Behrens, E.A.; Sylvester, P.; Graziano, G. and Clearfield, A. Evaluation of a Sodium Nonatitanate, Sodium Titanosilicate, and Pharmacosiderite-type Ion Exchangers for Strontium Removal from DOE Waste and Hanford N-Springs Groundwater Simulants, Science and Technology for Disposal of Radioactive 
Tank Wastes, W. W. Schulz, N.L. Lombardo, Eds.: Plenum Press, 287-299, (1998).

[10] Clearfield, A. and Lehto, J. Preparation, Structure and Ion Exchange Properties of $\mathrm{Na}_{4} \mathrm{Ti}_{9} \mathrm{O}_{20} \cdot \mathrm{nH}_{2} \mathrm{O}$. Journal of Solid State Chemistry 73, 98-106 (1998).

[11] Sylvester, P. and Clearfield, A. The Removal of Strontium from Simulated Hanford Tank Wastes Containing Complexants, Separation Science and Technology, 34(13), 2539-2551 (1999).

[12] Hobbs, D.T.; Blume, M.S. and Thacker, H.L. Screening Evaluation of Sodium Nonatitanate for Strontium and Actinide Removal from Alkaline Salt Solution, WSRC-TR-2000-00361, Savannah River Site, Aiken, SC 29808 (January 2001).

[13] Barnes, M.J.; Edwards, T.B.; Hobbs, D.T.; Marshall, K.M. Strontium and Actinide Removal Testing with Monosodium Titanate and Other Sorbents. WSRC-TR-2001-00436, Savannah River Site, Aiken, SC 29808 (Sept. 28, 2001). 
WSRC-TR-2001-00583

Table 1. Simulant profiles for N-Springs, NCAW, DSSF-7 and 101SY-Cs5.

\begin{tabular}{|c|c|c|c|c|}
\hline \multirow{2}{*}{ Species } & N-Springs & \multicolumn{2}{c|}{ NCAW } & \multicolumn{2}{c|}{ DSSF-7 } & 101SY-Cs5 \\
\cline { 2 - 5 } & \multicolumn{4}{|c|}{ Concentration (M) } \\
\hline $\mathrm{Al}$ & 0 & 0.43 & 0.72 & 0.42 \\
\hline $\mathrm{Ba}$ & $1.12 \mathrm{E}-07$ & 0 & 0 & 0 \\
\hline $\mathrm{Ca}$ & $7.27 \mathrm{E}-07$ & 0 & 0 & $4.20 \mathrm{E}-03$ \\
\hline $\mathrm{Cs}$ (inactive) & 0 & $5.00 \mathrm{E}-04$ & $7.0 \mathrm{E}-5$ & $4.19 \mathrm{E}-05$ \\
\hline $\mathrm{Fe}$ & 0 & 0 & 0 & $1.96 \mathrm{E}-04$ \\
\hline $\mathrm{K}$ & 0 & 0.12 & 0.945 & 0.034 \\
\hline $\mathrm{Mg}$ & $2.16 \mathrm{E}-04$ & 0 & 0 & 0 \\
\hline $\mathrm{Mo}$ & 0 & 0 & 0 & $4.20 \mathrm{E}-04$ \\
\hline $\mathrm{Na}$ & $2.61 \mathrm{E}-04$ & 4.99 & 7.0 & 5.1 \\
\hline $\mathrm{Ni}$ & 0 & 0 & 0 & $2.50 \mathrm{E}-04$ \\
\hline $\mathrm{Rb}$ & 0 & $5.00 \mathrm{E}-05$ & 0 & $4.20 \mathrm{E}-06$ \\
\hline Sr (inactive) & $1.48 \mathrm{E}-06$ & 0 & & $2.90 \mathrm{E}-07$ \\
\hline Zn & 0 & 0 & 0 & $5.00 \mathrm{E}-04$ \\
\hline carbonate & $1.25 \mathrm{E}-04$ & 0.23 & 0.147 & 0.038 \\
\hline chloride & $4.51 \mathrm{E}-05$ & 0 & 0.102 & 0 \\
\hline fluoride & $1.05 \mathrm{E}-05$ & 0.09 & 0 & 0.092 \\
\hline hydroxide & $\mathrm{n} / \mathrm{a}$ & 3.4 & 4.634 & 3.78 \\
\hline hydroxide (free) & $1.66 \mathrm{E}-03$ & 1.68 & 1.75 & 2.11 \\
\hline nitrate & $1.94 \mathrm{E}-04$ & 1.67 & 3.52 & 1.29 \\
\hline nitrite & 0 & 0.43 & 1.512 & 1.09 \\
\hline sulfate & $2.16 \mathrm{E}-04$ & 0.15 & 0.008 & $4.75 \mathrm{E}-03$ \\
\hline phosphate & 0 & 0.025 & 0.014 & 0.02 \\
\hline citric acid & 0 & 0 & 0 & $5.00 \mathrm{E}-03$ \\
\hline tetrasodium EDTA & 0 & 0 & 0 & $5.00 \mathrm{E}-03$ \\
\hline N-(2-hydroxyethyl) & 0 & 0 & 0 & $3.75 \mathrm{E}-3$ \\
\hline EDTA & & & & \\
\hline iminodiacetic acid & 0 & 0 & 0 & 0.031 \\
\hline nitriloacetate & 0 & 0 & 0 & $2.50 \mathrm{E}-04$ \\
\hline sodium gluconate & 0 & 0 & 0 & 0.013 \\
\hline Theoretical pH & 11.2 & 14.5 & 14.56 & 14.4 \\
\hline & & & & \\
\hline & 0 & 0 & 0 & 0 \\
\hline
\end{tabular}




\section{Table 2. ${ }^{89} \mathrm{Sr}$ Distribution Coefficients (Kd) and Percent Removal for the N-Springs.*}

\begin{tabular}{|c|c|c|c|c|}
\hline \multirow{2}{*}{ Sample } & \multicolumn{2}{|c|}{ V:m = 200:1 } & \multicolumn{2}{c|}{ V:m = 1000:1 } \\
\cline { 2 - 5 } & $\mathbf{K}_{\mathbf{d}}(\mathbf{m l} / \mathbf{g})$ & $\begin{array}{c}\text { \% Sr } \\
\text { Removed }\end{array}$ & $\mathbf{K}_{\mathbf{d}}(\mathbf{m l} / \mathbf{g})$ & $\begin{array}{c}\text { \% Sr } \\
\text { Removed }\end{array}$ \\
\hline Chabazite & 30,650 & 99.35 & 10,400 & 91.04 \\
\hline Clinoptilolite & 27,190 & 99.34 & 4,400 & 81.71 \\
\hline HTiSi & 7,900 & 97.54 & 28,800 & 99.89 \\
\hline KTSsol & 57,610 & 99.69 & 121,500 & 99.20 \\
\hline NaTi & 25,300 & 99.24 & 322,400 & 99.69 \\
\hline NaTS & $>326,000$ & $>99.94$ & 863,400 & 99.89 \\
\hline
\end{tabular}

${ }^{*}$ As in Table 1 traced with ${ }^{89} \mathrm{Sr}$ for Tables 2-5.

Table 3. ${ }^{89}$ Sr Distribution Coefficients (Kd) and Percent Removal for NCAW.

\begin{tabular}{|c|c|c|c|c|}
\hline \multirow{2}{*}{ Sample } & \multicolumn{2}{|c|}{ V:m= 200:1 } & \multicolumn{2}{c|}{ V:m = 1000:1 } \\
\cline { 2 - 5 } & $\mathbf{K}_{\mathbf{d}}(\mathbf{m l} / \mathbf{g})$ & $\begin{array}{c}\text { \% Sr } \\
\text { Removed }\end{array}$ & $\mathbf{K}_{\mathbf{d}}(\mathbf{m l} / \mathbf{g})$ & $\begin{array}{c}\text { \% Sr } \\
\text { Removed }\end{array}$ \\
\hline NaTS & 269,500 & 99.93 & 225,800 & 99.56 \\
\hline NaTi & 235,100 & 99.92 & 39,600 & 97.52 \\
\hline HTiSi & 44,800 & 99.55 & 3,700 & 78.09 \\
\hline KTSsol & 20,200 & 98.80 & 5,000 & 83.85 \\
\hline
\end{tabular}




\section{Table 4. ${ }^{89}$ Sr Distribution Coefficients (Kd) and Percent Removal for DSSF-7.}

\begin{tabular}{|c|c|c|c|c|}
\hline \multirow{2}{*}{ Sample } & \multicolumn{2}{|c|}{ V:m = 200:1 } & \multicolumn{2}{c|}{ V:m = 1000:1 } \\
\cline { 2 - 5 } & $\mathbf{K}_{\mathbf{d}}(\mathbf{m l} / \mathbf{g})$ & $\begin{array}{c}\text { \% Sr } \\
\text { Removed }\end{array}$ & $\mathbf{K}_{\mathbf{d}}(\mathbf{m l} / \mathbf{g})$ & $\begin{array}{c}\text { \% } \mathbf{~ r} \\
\text { Removed }\end{array}$ \\
\hline NaTS & 111,000 & 99.82 & 134,700 & 99.29 \\
\hline NaTi & 54,800 & 99.64 & 38,400 & 97.48 \\
\hline HTiSi & 22,800 & 99.14 & 7,000 & 87.63 \\
\hline KTSsol & 6,400 & 97.00 & 4,800 & 82.38 \\
\hline
\end{tabular}

Table 5. ${ }^{89} \mathrm{Sr}$ Distribution Coefficients (Kd) and Percent Removal for 101SY-Cs5.

\begin{tabular}{|c|c|c|}
\hline \multirow{2}{*}{ Sample } & \multicolumn{2}{|c|}{ V:m= 200:1 } \\
\cline { 2 - 3 } & $\mathbf{K}_{\mathbf{d}}(\mathbf{m l} / \mathbf{g})$ & $\begin{array}{c}\text { \% } \mathbf{~ S r} \\
\text { Removed }\end{array}$ \\
\hline NaTS & 231 & 54.66 \\
\hline NaTi & 295 & 61.12 \\
\hline HTiSi & 164 & 45.60 \\
\hline KTSsol & 31 & 13.20 \\
\hline
\end{tabular}


Table 6. Reaction conditions for sodium titanate preparation.

\begin{tabular}{|c|c|c|c|c|c|c|}
\hline $\begin{array}{c}\text { Sample } \\
\text { No. }\end{array}$ & $\begin{array}{c}\text { CONC } \\
\text { Ti Soln(M) }\end{array}$ & $\begin{array}{c}\text { CONC NaOH } \\
\text { Soln(M) }\end{array}$ & Ti:Na & $\begin{array}{c}\text { Reflux } \\
\text { Time (R) }\end{array}$ & Temp. ${ }^{\circ}$ C & $\begin{array}{c}\text { X-ray } \\
\text { Type }\end{array}$ \\
\hline 11A & 1.0 & 4.0 & $1: 4$ & 3 & $200(20 \mathrm{~h})$ & T1;T2 \\
\hline 11B & 1.0 & 2.0 & $1: 2$ & 3 & $200(20 \mathrm{~h})$ & T1 \\
\hline 13B & 0.9 & 9.0 & $1: 10$ & 3.2 & $190(21 \mathrm{~h})$ & T3 \\
\hline 23B & 0.92 & 9.7 & $1: 10.5$ & 0 & $190(22 \mathrm{~h})$ & T3 \\
\hline 48A & 0.63 & 3.1 & $1: 5$ & 2 & $170(22.5 \mathrm{~h})$ & T1 \\
\hline 48B & 0.70 & 3.3 & $1: 4.7$ & 0 & $170(23 \mathrm{~h})$ & T1 \\
\hline 67A & 0.43 & 0.87 & $1: 2$ & 3.5 & $145(4 \mathrm{~d})$ & Amorph. \\
\hline 67B & 0.75 & 5.1 & $1: 6.8$ & 1 & $200(4 \mathrm{~d})$ & T2 \\
\hline 62A & 1.6 & 2.5 & $1: 1.56$ & 3 & $190(20 \mathrm{~h})$ & T1 \\
\hline 64A & 0.65 & 4.5 & $1: 69$ & 3.2 & $193(19.7 \mathrm{~h})$ & T2 \\
\hline 64B & 0.58 & 5.1 & $1: 8.9$ & 3.2 & $193(19.7 \mathrm{~h})$ & T2 \\
\hline 71A & 0.69 & 1.4 & $1: 2.1$ & 3 & $200(7 \mathrm{~d})$ & T1 \\
\hline 90A & 0.44 & 8.35 & $1: 19.4$ & 16.5 & $200(1 \mathrm{~d})$ & T3 \\
\hline 92A & 1.1 & 1.5 & $1: 1.37$ & 3.25 & $200(20 \mathrm{~h})$ & T1 \\
\hline
\end{tabular}


WSRC-TR-2001-00583

Table 7. Chemical analysis of the three types of titanates formed from hydrothermal treatment.

\begin{tabular}{|c|c|c|c|}
\hline Sample & wt \% Na & wt \% Ti & Ti:Na mole ratio \\
\hline 92A(T1) & 12.47 & 43.23 & $1: 0.623$ \\
\hline $67 \mathrm{~B}(\mathrm{~T} 2)$ & 12.04 & 40.36 & $1: 0.622$ \\
\hline $64 \mathrm{~B}(\mathrm{~T} 2)$ & 9.55 & 39.70 & $1: 0.501$ \\
\hline $23 \mathrm{~B}(\mathrm{~T} 3)$ & 16.16 & 37.82 & $1: 0.890$ \\
\hline 92AW2(T1) & 11.37 & 50.08 & $1: 0.473$ \\
\hline 67BW(T2) & 9.33 & 47.20 & $1: 0.412$ \\
\hline 23BW2(T3) & 12.26 & 48.40 & $1: 0.528$ \\
\hline
\end{tabular}

Table 8. $\mathrm{Sr}^{2+} \mathrm{K}_{\mathrm{d}}$ 's for titanate samples in the presence of $5 \mathrm{M} \mathrm{NaNO}_{3}, 1 \mathrm{M}$ $\mathrm{NaOH}$, and 91-95 $\mathrm{ppm} \mathrm{Sr}^{2+}$ (solution to sample ratio was 200:1).

\begin{tabular}{|l|l|l|}
\hline Sample No. & Structure Type & Sr $_{\mathbf{D}}(\mathbf{m l} / \mathbf{g})$ \\
\hline $11 \mathrm{~A}$ & T1, T2 & 27,300 \\
\hline $11 \mathrm{~B}$ & $\mathrm{~T} 1$ & 7,310 \\
\hline 92A & $\mathrm{T} 1$ & 4,350 \\
\hline 67B & $\mathrm{T} 2$ & 58,700 \\
\hline $62 \mathrm{~A}^{*}$ & $\mathrm{~T} 1$ & 16,100 \\
\hline $51 \mathrm{D}^{*}$ & $\mathrm{~T} 1$ & 4,600 \\
\hline $48 \mathrm{~A}$ & $\mathrm{~T} 1$ & $\geq 131,000$ \\
\hline 48B & $\mathrm{T} 1$ & 29,100 \\
\hline 64A & $\mathrm{T} 2$ & 229,000 \\
\hline 64B & $\mathrm{T} 2$ & $\geq 131,000$ \\
\hline 23BW & T3 & $\geq 131,000$ \\
\hline
\end{tabular}

*The solution to exchanger ratio was $250: 1$. 
WSRC-TR-2001-00583

Table 9. $K_{d}$ values for sodium titanosilicate as a function of time. $\mathrm{V} / \mathrm{m}=\mathbf{2 5 0}, \mathbf{p H}=\mathbf{1 0}$

\begin{tabular}{|c|c|c|c|c|c|}
\hline Sample No. & Temp. ${ }^{\circ} \mathrm{C}$ & Time (h) & X-ray & $\mathrm{K}_{\mathrm{d}}\left(\frac{m l}{g}\right)^{\mathrm{b}}$ & $\mathrm{K}_{\mathrm{d}}\left(\frac{m l}{g}\right)^{\mathrm{c}}$ \\
\hline DMI-6-1 & 180 & 1 & $\begin{array}{l}\text { Semi-cryst, } \mathrm{d}=9.78 \AA \\
\text { See figure }\end{array}$ & 49,700 & 1540 \\
\hline DMI-6-2 & 180 & 10 & $\begin{array}{l}\text { Semi-cryst, d=9.78 } \\
\text { See figure }\end{array}$ & 27,700 & 3114 \\
\hline DMI-6-3 & 180 & 24 & Like X-ray Figure 9 & 48,500 & 4670 \\
\hline DMI-6-4 & 180 & 72 & Almost crystalline & 50,800 & 7785 \\
\hline DMI-6-5 & 180 & 168 & crystalline ${ }^{a}$ & 51,800 & 10,840 \\
\hline DMI-2a* & 190 & 120 & crystalline ${ }^{\mathrm{n}}$ & 51,900 & 9440 \\
\hline DMI-2b & 190 & 120 & crystalline $^{a}$ & 54,500 & 10,100 \\
\hline
\end{tabular}

* Using $\mathrm{TiCl}_{4}$ as source of $\mathrm{Ti}$, otherwise similar to DMI-2b.

a. Similar to Figure 7 a.

b. Solution contained $10^{-4} \mathrm{M} \mathrm{NaNO}_{3}$ and $10^{-5} \mathrm{M} \mathrm{Ca}\left(\mathrm{NO}_{3}\right)_{2}$ spiked with ${ }^{89} \mathrm{Sr}$.

c. Solution contained $0.04 \mathrm{M} \mathrm{NaNO}_{3}, 0.025 \mathrm{M} \mathrm{KNO}_{3}, 7.5 \times 10^{-3} \mathrm{M} \mathrm{Ca}\left(\mathrm{NO}_{3}\right)_{2}$. 


Sorbent
MST \#33180
SrTreat \#48
SrTreat \#49
CST IE-910
CST IE-911
MST \#33180
SrTreat \#8
TAMU DM1-11-1
MST \#33180
ST-RC-4-23B
ST-RC-4-64B
ST-39287-5A
ST-39287-5B
MST \#33180
MST \#33470
MST \#TNX
TAMU DM1-25
TAMU EABII-23

Sr
$\underline{24 h}$
$1.51 \mathrm{E}+02$
$4.20 \mathrm{E}+00$
$1.07 \mathrm{E}+02$
$1.06 \mathrm{E}+01$
$5.81 \mathrm{E}+00$
$3.23 \mathrm{E}+01$
$8.74 \mathrm{E}+01$
$2.61 \mathrm{E}+01$
$1.58 \mathrm{E}+02$
$1.09 \mathrm{E}+02$
$2.91 \mathrm{E}+02$
$7.60 \mathrm{E}+01$
$2.55 \mathrm{E}+01$
$1.07 \mathrm{E}+02$
$3.62 \mathrm{E}+00$
$1.14 \mathrm{E}+01$
$8.73 \mathrm{E}+01$
$2.91 \mathrm{E}+01$

Sr
$\mathbf{7 d}$
$3.05 \mathrm{E}+02$
$4.08 \mathrm{E}+01$
$5.91 \mathrm{E}+02$
$1.59 \mathrm{E}+01$
$1.97 \mathrm{E}+01$

$4.31 \mathrm{E}+01$
$1.96 \mathrm{E}+02$
$4.76 \mathrm{E}+01$
$1.90 \mathrm{E}+02$
$9.91 \mathrm{E}+01$
$4.73 \mathrm{E}+02$
$1.78 \mathrm{E}+02$
$6.07 \mathrm{E}+01$
$1.41 \mathrm{E}+02$
$2.81 \mathrm{E}+01$
$3.17 \mathrm{E}+01$
$1.53 \mathrm{E}+02$
$7.73 \mathrm{E}+01$

Pu

$24 \mathrm{~h}$

1.13E+01

$1.40 \mathrm{E}+00$

$1.74 \mathrm{E}+00$

$1.28 \mathrm{E}+00$

$1.95 \mathrm{E}+00$

$4.93 \mathrm{E}+00$

$2.01 \mathrm{E}+00$

$1.30 \mathrm{E}+00$

$1.03 \mathrm{E}+01$

$3.54 \mathrm{E}+00$

$7.69 \mathrm{E}+00$

$1.09 \mathrm{E}+01$

$3.08 \mathrm{E}+01$

$9.21 \mathrm{E}+00$

$2.36 \mathrm{E}+00$

$3.87 \mathrm{E}+00$

$4.21 \mathrm{E}+00$

$1.69 \mathrm{E}+00$
Sorbent

MST \#33180

SrTreat \#48

SrTreat \#49

CST IE-910

CST IE-911

MST \#33180

SrTreat \#8

TAMU DM1-11-1

MST \#33180

ST-RC-4-23B

ST-RC-4-64B

ST-39287-5A

ST-39287-5B

MST \#33180

MST \#33470

MST \#TNX

TAMU DM1-25

TAMU EABII-23

\section{Sr}

$\underline{24 h}$

3.75E+05 $6.97 \mathrm{E}+03$

$2.22 \mathrm{E}+05$

$8.82 \mathrm{E}+03$

4.34E+03

$7.83 \mathrm{E}+04$

$3.52 \mathrm{E}+05$

$5.42 \mathrm{E}+04$

3.92E+05

$2.23 \mathrm{E}+0.5$

$5.53 \mathrm{E}+05$

$9.56 \mathrm{E}+04$

4.70E+04

$2.65 \mathrm{E}+05$

$6.57 \mathrm{E}+03$

$2.59 \mathrm{E}+04$

9.13E+04

3.37E+04

$$
\text { Sr }
$$$$
\text { 7d }
$$

$7.61 \mathrm{E}+05$

8.67E+04

$1.23 \mathrm{E}+06$

$1.37 \mathrm{E}+04$

$1.68 \mathrm{E}+04$

$1.05 \mathrm{E}+05$

$7.95 \mathrm{E}+05$

$1.01 \mathrm{E}+05$

4.72E+05

$2.03 \mathrm{E}+05$

$9.01 \mathrm{E}+05$

$2.26 \mathrm{E}+05$

$1.15 \mathrm{E}+05$

$3.51 \mathrm{E}+05$

$6.80 \mathrm{E}+04$

$7.63 \mathrm{E}+04$

$1.60 \mathrm{E}+05$

9.14E+04

\section{Pu}

$24 \mathrm{~h}$

$2.58 \mathrm{E}+04$

$8.80 \mathrm{E}+02$

$1.54 \mathrm{E}+03$

$2.57 \mathrm{E}+02$

$8.60 \mathrm{E}+02$

$9.85 \mathrm{E}+03$

4. $10 \mathrm{E}+03$

$6.47 \mathrm{E}+02$

2.33E+04

$5.25 \mathrm{E}+03$

$1.28 \mathrm{E}+04$

$1.26 \mathrm{E}+04$

$5.72 \mathrm{E}+04$

$2.06 \mathrm{E}+04$

$3.41 \mathrm{E}+03$

$7.14 \mathrm{E}+03$

$3.40 \mathrm{E}+03$

$8.22 \mathrm{E}+02$
Table 10

Decontamination

Factor

$\begin{array}{ccc}\mathbf{P u} & \mathbf{U} & \mathbf{U} \\ \underline{\mathbf{7 d}} & \underline{24 \mathbf{h}} & \underline{\mathbf{7 d}} \\ 3.23 \mathrm{E}+01 & 1.14 \mathrm{E}+00 & 1.36 \mathrm{E}+00 \\ 1.81 \mathrm{E}+00 & 9.33 \mathrm{E}-01 & 9.97 \mathrm{E}-01 \\ 2.90 \mathrm{E}+00 & 9.31 \mathrm{E}-01 & 1.02 \mathrm{E}+00 \\ 1.16 \mathrm{E}+00 & 9.58 \mathrm{E}-01 & 9.56 \mathrm{E}-01 \\ 3.39 \mathrm{E}+00 & 1.00 \mathrm{E}+00 & 1.12 \mathrm{E}+00 \\ & & \\ 1.44 \mathrm{E}+01 & 1.12 \mathrm{E}+00 & 1.22 \mathrm{E}+00 \\ 8.20 \mathrm{E}+01 & 1.20 \mathrm{E}+00 & 2.26 \mathrm{E}+00 \\ 1.82 \mathrm{E}+00 & 1.17 \mathrm{E}+00 & 1.24 \mathrm{E}+00 \\ & & \\ 2.96 \mathrm{E}+01 & 2.08 \mathrm{E}+00 & 1.36 \mathrm{E}+00 \\ 9.11 \mathrm{E}+00 & 1.50 \mathrm{E}+00 & 1.52 \mathrm{E}+00 \\ 5.69 \mathrm{E}+01 & 1.80 \mathrm{E}+00 & 2.71 \mathrm{E}+00 \\ 2.56 \mathrm{E}+01 & 2.92 \mathrm{E}+00 & 2.43 \mathrm{E}+00 \\ 5.81 \mathrm{E}+01 & 2.04 \mathrm{E}+00 & 2.23 \mathrm{E}+00 \\ & & \\ 2.11 \mathrm{E}+01 & 1.40 \mathrm{E}+00 & 1.74 \mathrm{E}+00 \\ 1.29 \mathrm{E}+01 & 1.14 \mathrm{E}+00 & 1.34 \mathrm{E}+00 \\ 1.37 \mathrm{E}+01 & 1.15 \mathrm{E}+00 & 1.18 \mathrm{E}+00 \\ 2.47 \mathrm{E}+02 & 1.27 \mathrm{E}+00 & 3.20 \mathrm{E}+00 \\ 1.91 \mathrm{E}+01 & 1.13 \mathrm{E}+00 & 1.34 \mathrm{E}+00\end{array}$

Distribution

Constant (mL/g)

Pu

7d

$7.85 \mathrm{E}+04$

$1.77 \mathrm{E}+03$

$3.97 \mathrm{E}+03$

$1.46 \mathrm{E}+02$

$2.15 \mathrm{E}+03$

$3.36 \mathrm{E}+04$

$3.30 \mathrm{E}+05$

$1.76 \mathrm{E}+03$

3.08E+02

$8.05 \mathrm{E}+02$

$3.73 E+02$

7.14E+04

2.71E+03

$1.68 \mathrm{E}+04$

$1.07 \mathrm{E}+05$

3.13E+04

$1.10 \mathrm{E}+05$

$1.03 \mathrm{E}+03$

$1.53 \mathrm{E}+03$

$2.45 \mathrm{E}+03$

$1.99 \mathrm{E}+03$

$5.04 \mathrm{E}+04$

$2.98 \mathrm{E}+04$

$3.16 \mathrm{E}+04$

$1.60 \mathrm{E}+05$

$1.01 \mathrm{E}+03$

$3.47 \mathrm{E}+02$

$3.64 \mathrm{E}+02$

$2.16 \mathrm{E}+04$

$2.88 \mathrm{E}+02$

$1.56 \mathrm{E}+02$

Appendix I

$\begin{array}{cc}\text { Np } & \text { Np } \\ \underline{24 h} & \underline{7 d} \\ 3.47 \mathrm{E}+00 & 8.08 \mathrm{E}+00 \\ 9.37 \mathrm{E}-01 & 1.33 \mathrm{E}+00 \\ 1.06 \mathrm{E}+00 & 1.73 \mathrm{E}+00 \\ 1.00 \mathrm{E}+00 & 1.16 \mathrm{E}+00 \\ 1.13 \mathrm{E}+00 & 2.00 \mathrm{E}+00 \\ & \\ 1.98 \mathrm{E}+00 & 2.47 \mathrm{E}+00 \\ 1.43 \mathrm{E}+00 & 1.13 \mathrm{E}+01 \\ 1.23 \mathrm{E}+00 & 1.45 \mathrm{E}+00 \\ & \\ 5.56 \mathrm{E}+00 & 1.34 \mathrm{E}+01 \\ 3.47 \mathrm{E}+00 & 7.04 \mathrm{E}+00 \\ 2.81 \mathrm{E}+00 & 1.24 \mathrm{E}+01 \\ 4.19 \mathrm{E}+00 & 1.31 \mathrm{E}+01 \\ 5.44 \mathrm{E}+00 & 1.72 \mathrm{E}+01 \\ 2.02 \mathrm{E}+00 & 6.42 \mathrm{E}+00 \\ 1.37 \mathrm{E}+00 & 3.68 \mathrm{E}+00 \\ 1.50 \mathrm{E}+00 & 3.02 \mathrm{E}+00 \\ 1.61 \mathrm{E}+00 & 2.09 \mathrm{E}+01 \\ 1.27 \mathrm{E}+00 & 3.01 \mathrm{E}+00\end{array}$

Np

$\underline{24 h}$

$6.18 \mathrm{E}+03$

$9.06 \mathrm{E}+02$

$4.52 \mathrm{E}+01$

$1.08 \mathrm{E}+02$

$4.46 \mathrm{E}+00$

$1.15 \mathrm{E}+02$

$2.45 \mathrm{E}+03$

$1.76 \mathrm{E}+03$

4.97E+02

$3.69 \mathrm{E}+03$

4.20E+04

$9.82 \mathrm{E}+02$

$1.14 \mathrm{E}+04$

$3.11 \mathrm{E}+04$

$8.88 \mathrm{E}+02$

$1.08 \mathrm{E}+03$

3.27E+03

$1.83 \mathrm{E}+03$

$2.36 \mathrm{E}+03$

$1.86 \mathrm{E}+03$

8.52E+02

$4.51 \mathrm{E}+02$

$2.33 \mathrm{E}+03$

4.13E+02

$1.25 \mathrm{E}+04$

$3.46 \mathrm{E}+03$

$4.06 \mathrm{E}+03$

$2.18 \mathrm{E}+04$

$1.55 \mathrm{E}+04$

$8.52 \mathrm{E}+03$

3.12E+04

$2.56 \mathrm{E}+03$

$9.38 \mathrm{E}+02$

$1.25 \mathrm{E}+03$

$6.45 \mathrm{E}+02$

1.36E+04

$6.71 \mathrm{E}+03$

$5.01 \mathrm{E}+03$

$2.11 \mathrm{E}+04$

$3.21 \mathrm{E}+02$

$2.41 \mathrm{E}+03$ 
WSRC-TR-2001-00583

Table AI. Chemical Composition of Salt Solution Simulant

\begin{tabular}{|c|c|}
\hline Component & Concentration \\
\hline $\mathrm{NaNO}_{3}$ & $2.60 \mathrm{M}$ \\
\hline $\mathrm{NaOH}$ & $1.33 \mathrm{M}$ \\
\hline $\mathrm{Na}_{2} \mathrm{SO}_{4}$ & $0.521 \mathrm{M}$ \\
\hline $\mathrm{NaAl}_{4} \mathrm{OH}_{4}$ & $0.429 \mathrm{M}$ \\
\hline $\mathrm{NaNO}_{2}$ & $0.134 \mathrm{M}$ \\
\hline $\mathrm{Na}_{2} \mathrm{CO}_{3}$ & $0.0260 \mathrm{M}$ \\
\hline Total Na & $5.6 \mathrm{M}$ \\
\hline Total Sr & $86.7 \pm 3.77 \mu \mathrm{g} / \mathrm{L}$ \\
\hline Total Pu & $190 \pm 5.83 \mu \mathrm{g} / \mathrm{L}$ \\
\hline Total U & $9040 \pm 986 \mu \mathrm{g} / \mathrm{L}$ \\
\hline${ }^{237} \mathrm{~Np}$ & $416 \pm 20.7 \mu \mathrm{g} / \mathrm{L}$ \\
\hline
\end{tabular}

Strontium and actinide removal testing utilized the same experimental method previously reported using the MST sorbent. * We added approximately 0.030 grams of the ST to $125 \mathrm{~mL}$ of the salt solution equilibrated at $25^{\circ} \mathrm{C}$. This quantity of ST provides the equivalent titanium content obtained upon addition of the current baseline material, MST, at $0.4 \mathrm{~g} / \mathrm{L}$. Researchers pulled samples from the test bottles after $5,24,48,144,170$ and 244 hours of contact at $25^{\circ} \mathrm{C}$.

*D.T. Hobbs, M.S. Blume and H.L. Thacker, "Phase V Simulant Testing of Monosodium Titanate Adsorption Kinetics" Report WSRC-TR-2000-00142, Rev. 0, May 24, 2000. 
WSRC-TR-2001-00583

\section{Figure Captions}

Figure 1. Cubane type (TiO) $)_{4}$ portion of sodium titanium silicate, $\mathrm{Na}_{2} \mathrm{Ti}_{2} \mathrm{O}_{3}\left(\mathrm{SiO}_{4}\right) \cdot 2 \mathrm{H}_{2} \mathrm{O}(\mathrm{CST})$ : The oxygen atoms in black bond to $\mathrm{Si}$, the lined oxygens bond to 3Ti and the stippled oxygens are oxo-groups that connect the cubane groups in the c-axis direction.

Figure 2. Representation of CST looking down the c-axis. The cubane groups are at the comers and the tunnel is parallel to the c-axis direction. Sodium ions (black) and water molecules occupy the tunnel.

Figure 3. Ball and stick representation of CST structure in the ac (or bc) plane. Note the sodium ions held within the framework in addition to those in the tunnel. The structure is best visualized by holding Figure 2 horizontally and Figure 3 vertically.

Figure 4. Ball and stick representation of $\mathrm{Cs}^{+}$exchanged CST showing the position of the Cs (black circle) in the tunnel center.

Figure 5. Uptake of alkali metal cations as a function of $\mathrm{pH}$. The low uptake of $\mathrm{Cs}^{+}$results from its size. $\mathrm{Cs}^{+}$uptake is $25 \%$ of the total exchange capacity and these ions occupy only half the tunnel sites and none of the framework sites.

Figure 6. Ball and stick representation of $\mathrm{K}_{3} \mathrm{H}(\mathrm{TiO})_{4}\left(\mathrm{SiO}_{4}\right)_{3} \cdot 4 \mathrm{H}_{2} \mathrm{O}$. The corners of each unit cell have $(\mathrm{TiO})_{4}$ cubane-like groups and the $\mathrm{K}^{+}$are in the face centers within the tunnels. Because the lattice is cubic, there are three intersecting tunnels.

Figure 7. Inorganic ion exchangers examined for removal of $\mathrm{Sr}^{2+}$ from nuclear waste solutions. The exchangers are identified on the figure.

Figure 8. Representative X-ray powder patterns of sodium nanotitanates. The structure types are indicated to the right of the $\mathrm{X}$-ray patterns.

Figure 9. X-ray powder patterns of solids obtained during examination of heating time in preparation of the CST, $\mathrm{Na}_{2} \mathrm{Ti}_{2} \mathrm{O}_{3} \mathrm{SiO}_{4} \cdot 2 \mathrm{H}_{2} \mathrm{O}$, (A) Unknown precursor phase formed after one 
hour at $200^{\circ} \mathrm{C}$, and (B) After ten hours heating a mixture of the precursor phase and CST is obtained as shown by the narrow peak at $7.89 \AA$.

Figure 10. X-ray powder pattern of $\mathrm{NaTiOSiO}_{4}$, a non-ion exchange phase obtained at high base concentrations in the synthesis of CST.

Figure 11. Kinetic curves for strontium exchange from a simulant for a highly crystalline CST sample DM1-13-1, and a poòrly crystalline sample DM1-13-2.

Figure 12. Kinetics of $\mathrm{Sr}^{2+}$ uptake by a poorly crystalline CST sample DM1-11-1 submitted for testing at WSRC.

Figure 13. X-ray Diffraction powder pattern of the semi-crystalline CST sample DM1-11-1.

Figure 14. X-ray Diffraction pattern of a potassium titanium pharmacosiderite, of intermediate crystallinity, $\mathrm{K}_{3} \mathrm{H}(\mathrm{TiO})_{4}\left(\mathrm{SiO}_{4}\right)_{3} \cdot 4 \mathrm{H}_{2} \mathrm{O}$.

Figure 15. Kinetics of exchange of $\mathrm{Sr}^{2+}$ at WSRC for several inorganic ion exchangers in a simulant waste solution developed to duplicate Savannah River waste.

Figure 16. Kinetic measurements for (A) plutonium uptake and (B) Neptunium uptake as a function of time for several sodium nonatitanates in SR waste simulant. Work performed at WSRC. 


\section{Pigure 1}

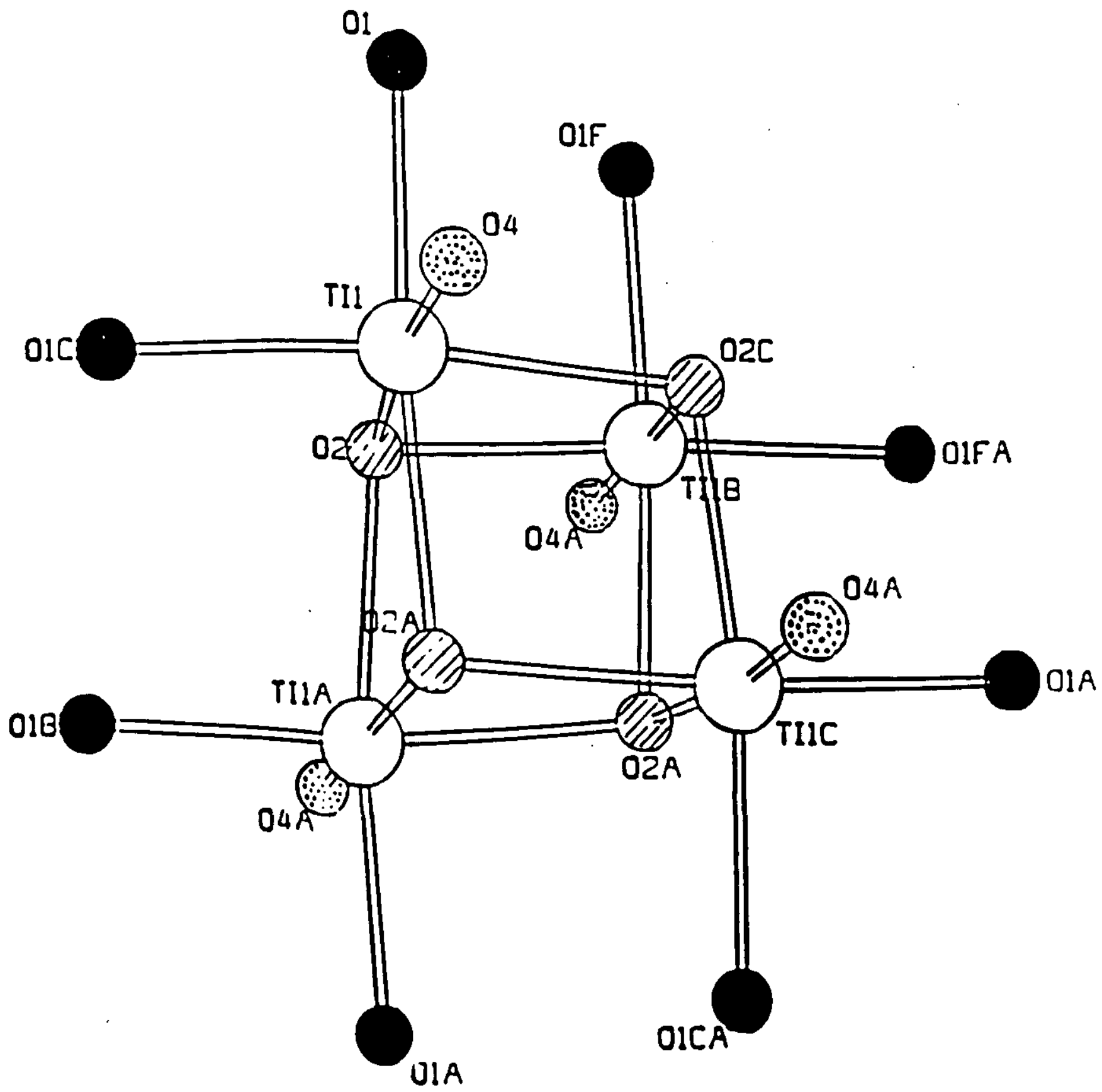

Cubane type $(\mathrm{TiO})_{4}$ portion of sodium titanium silicate, $\mathrm{Na}_{2} \mathrm{TI}_{2} \mathrm{O}_{3}\left(\mathrm{~S}_{4} \mathrm{O}_{4}\right) \cdot 2 \mathrm{H}_{2} \mathrm{O}$ (CST). The oxygen atoms in black bond to $S 1$, the lined oxygens bond to $3 T 1$ and the stippled oxygens are oxo-groups that connect the cubane groups in the c-axis direction. 


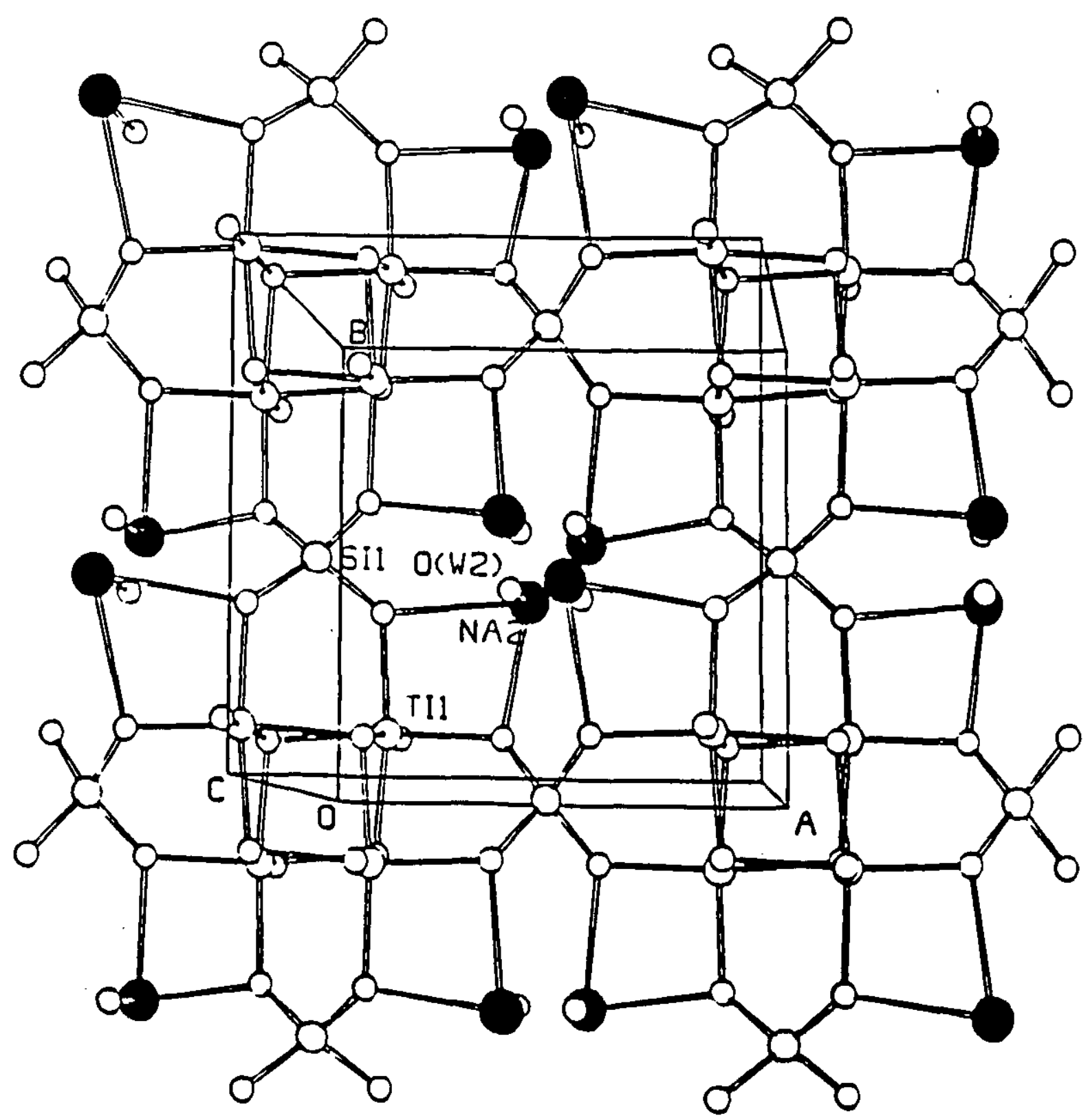

Representation of CST looking down the c-axis. The cubane groups are at the corners and the tunnel is parallel to the c-axis direction. Sodium ions (black) and water molecules occupy the tunnel. 
Figure 3

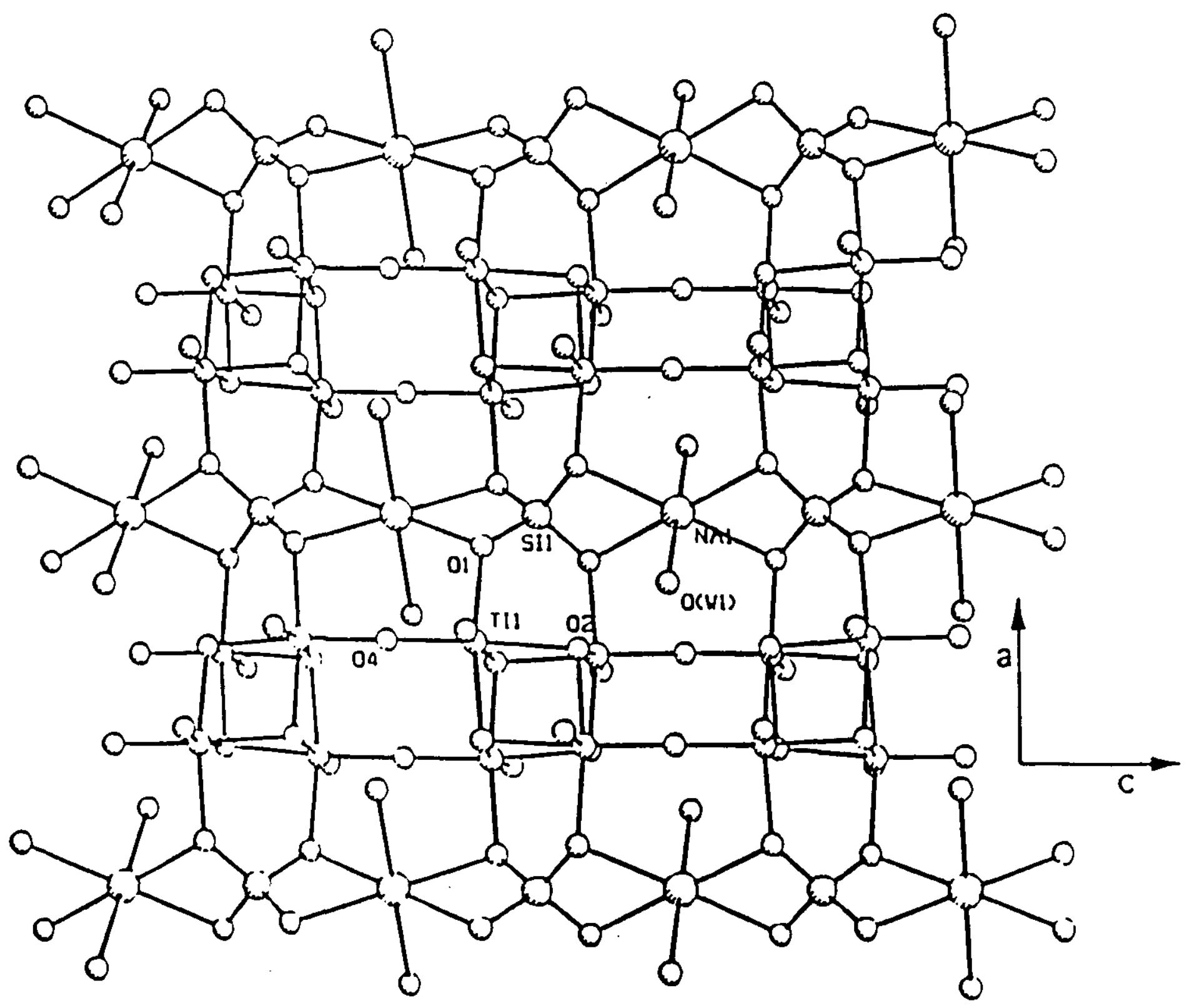

Ball and stick representation of CST structure in the ac (or bc) plane. Note the sodium ions held within the framework in addition to those in the tunnel. The structure is best visualized by holding Figure 2 horizontally and Figure 3 vertically. 


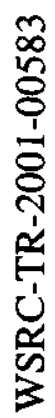

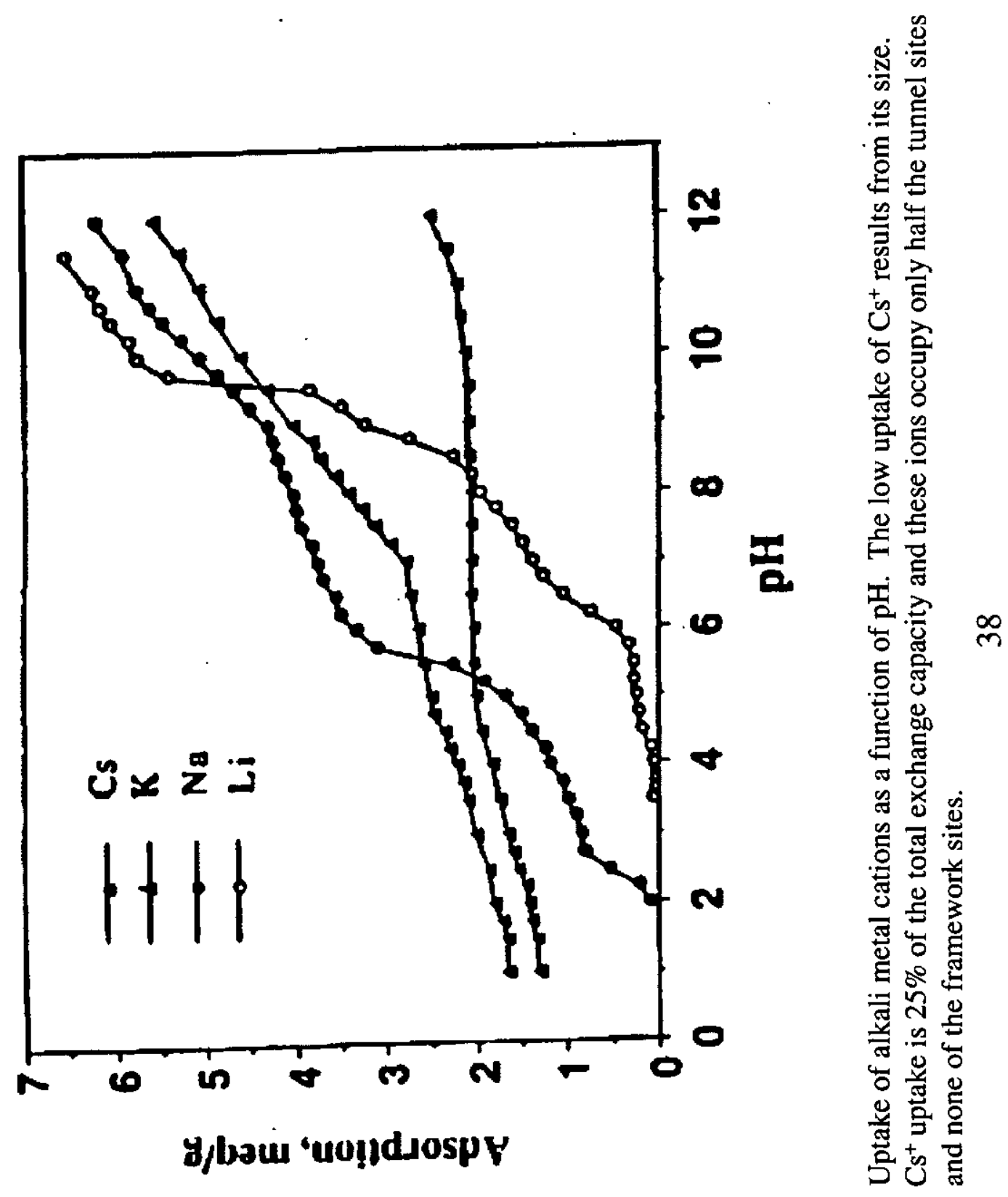


Figure 5

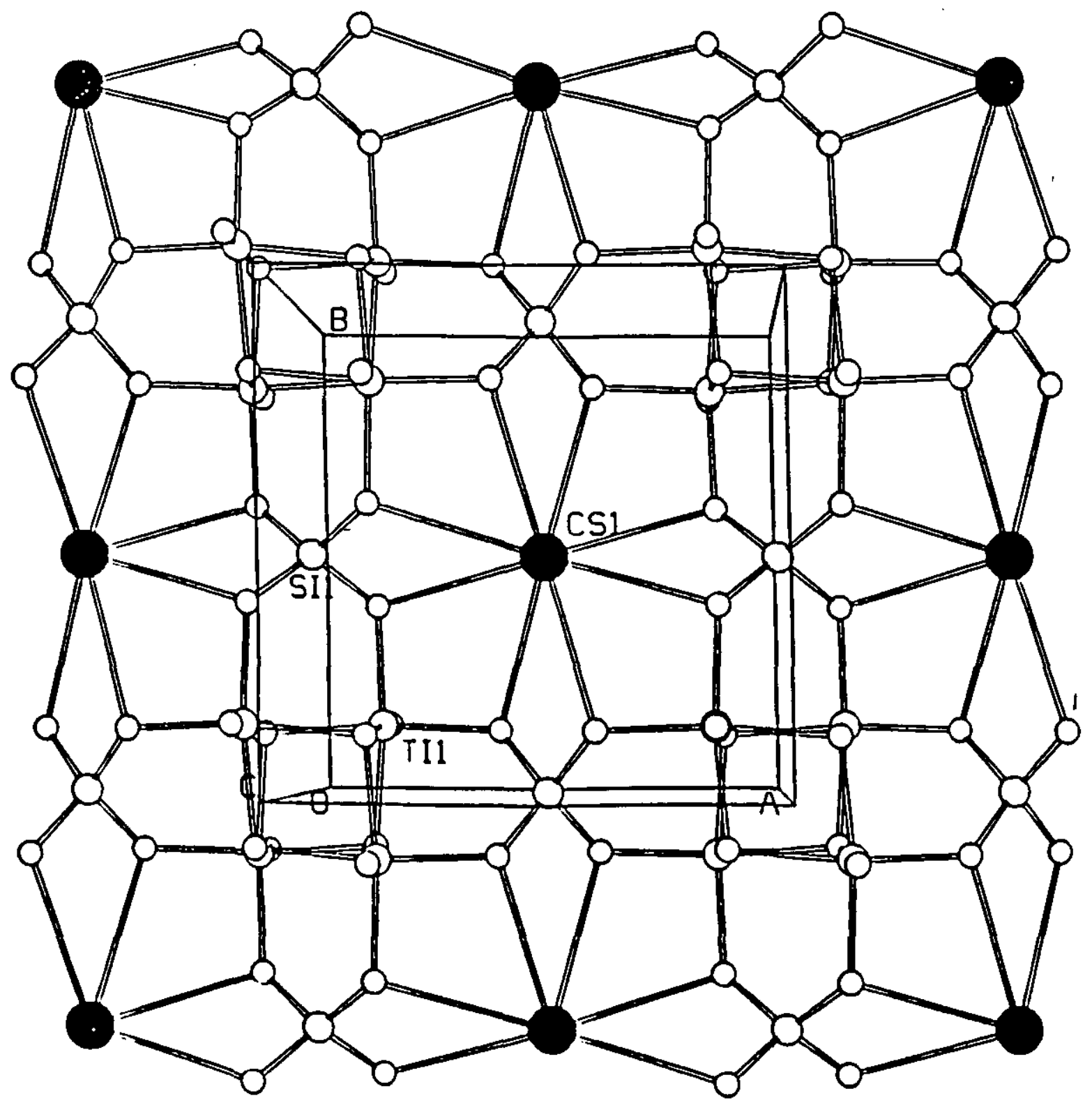

Ball and stick representation of $\mathrm{Cs}^{+}$exchanged CST showing the position of the Cs (black circle) in the tunnel center. 
Figure 6

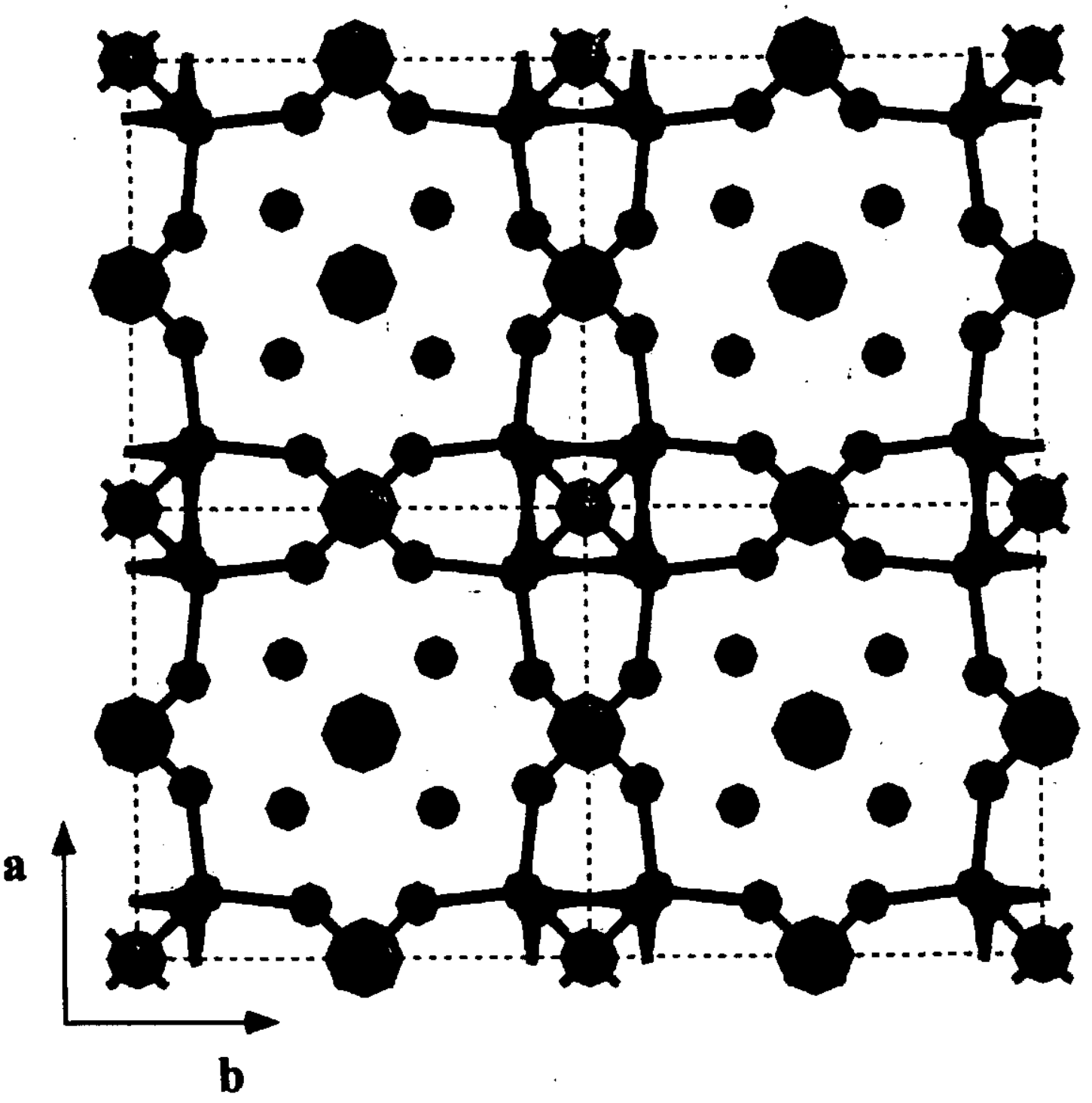

Ball and stick representation of $\mathrm{K}_{3} \mathrm{H}(\mathrm{TiO})_{4}\left(\mathrm{SiO}_{4}\right)_{3} 4 \mathrm{H}_{2} \mathrm{O}$. The corners of each unit cell have (TiO) ${ }_{4}$ cubane-like groups and the $\mathrm{K}^{+}$are in the face centers within the tunnels. Because the lattice is cubic, there are three intersecting tunnels. 

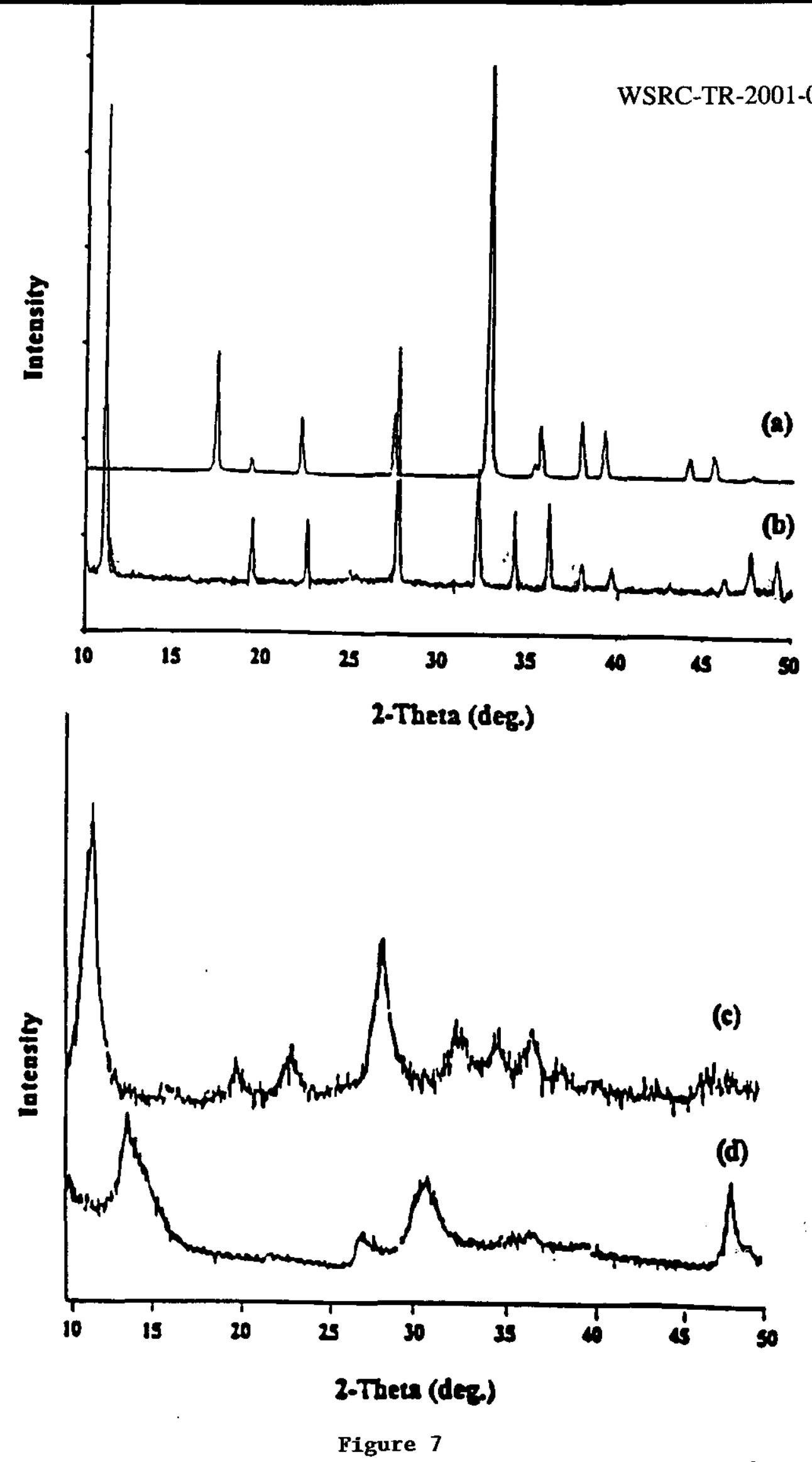

Inorganic ion exchangers examined for removal of $\mathrm{Sr}^{2+}$ from nuclear waste solutions. The exchangers are identified on the figure. 


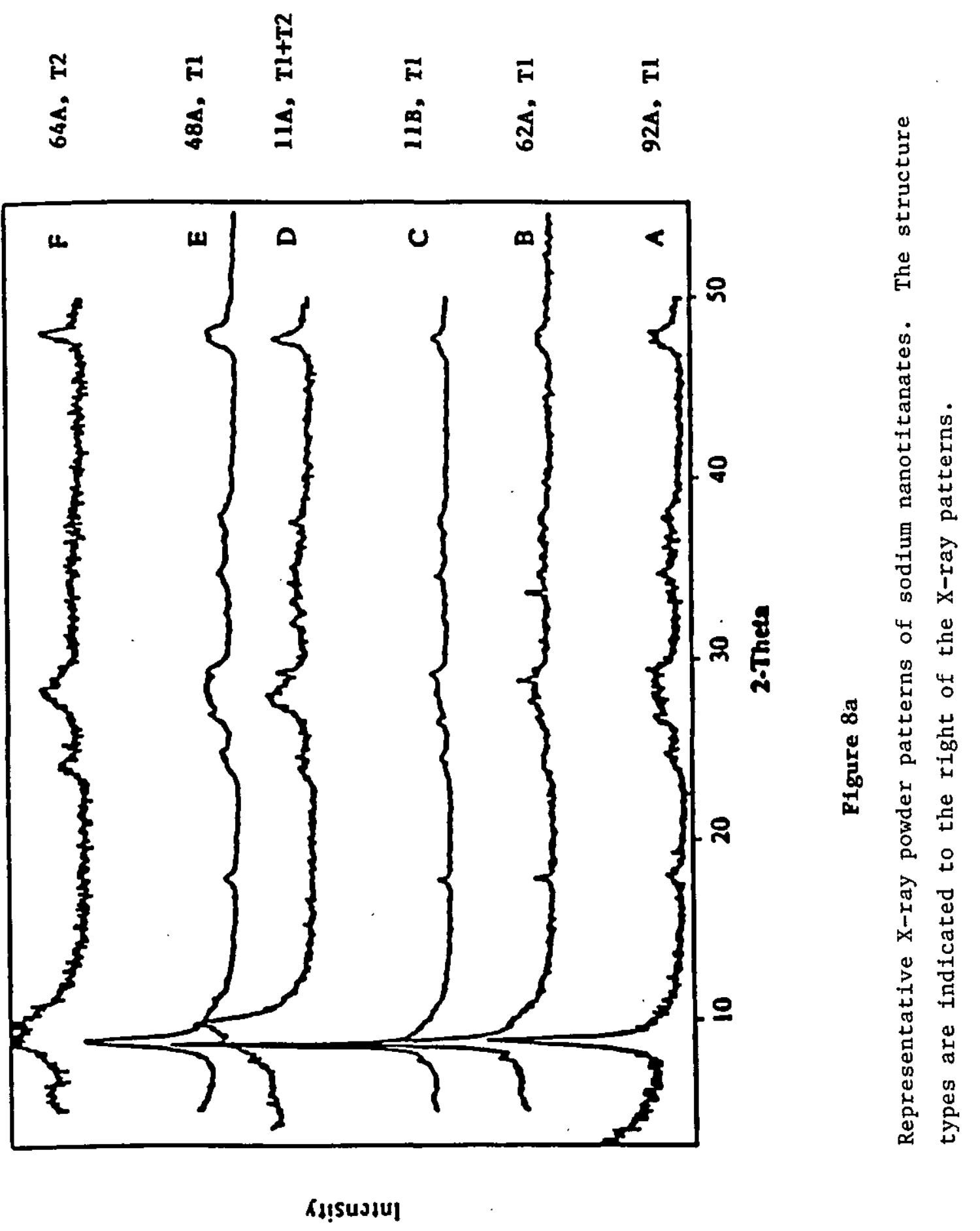




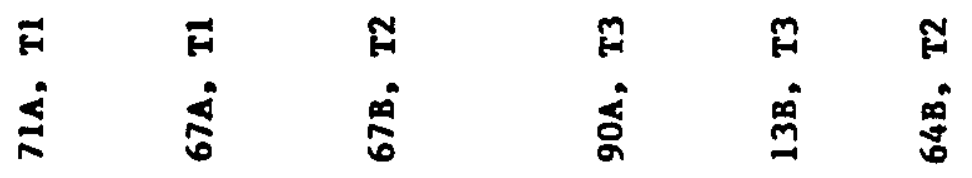

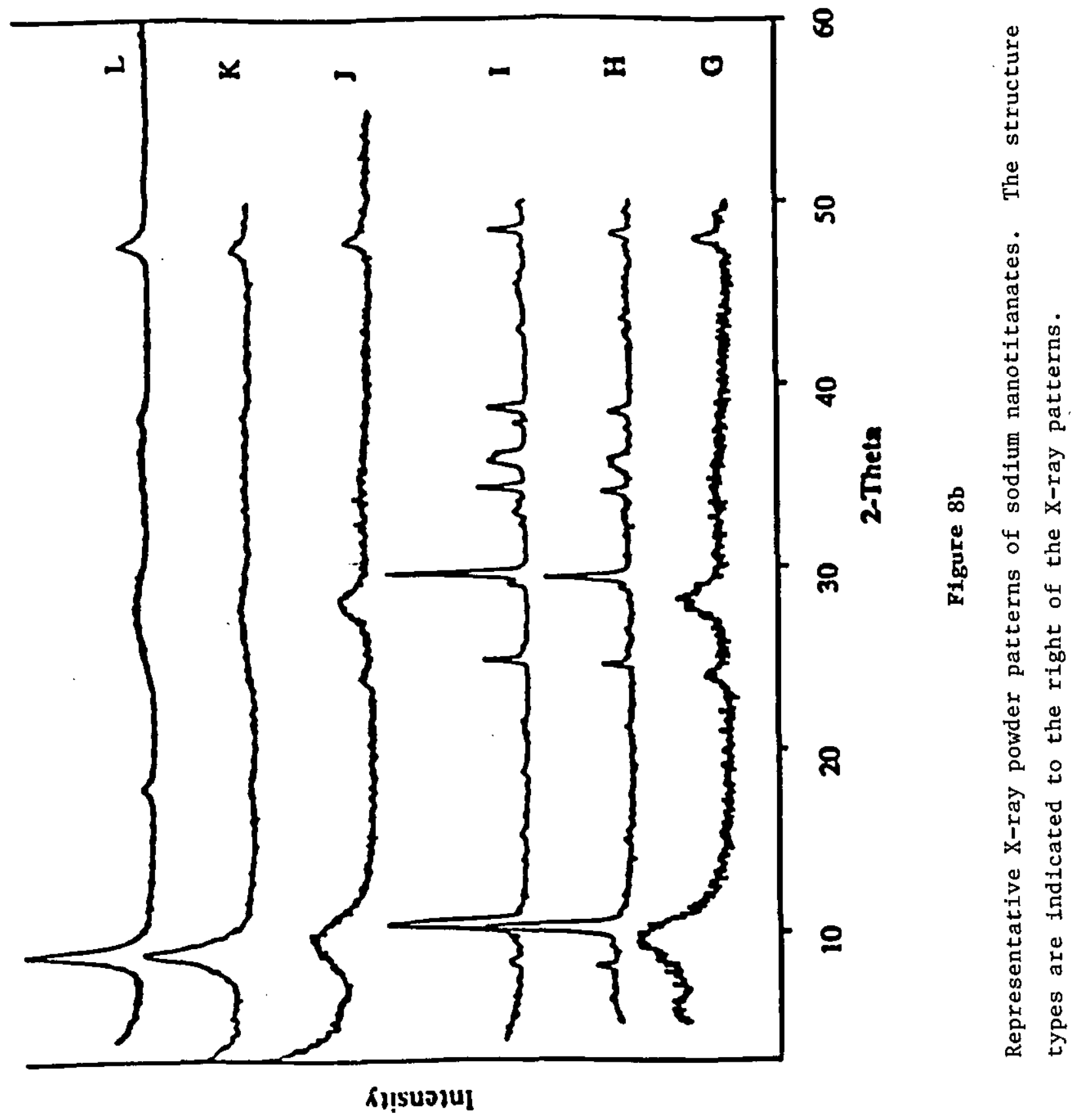



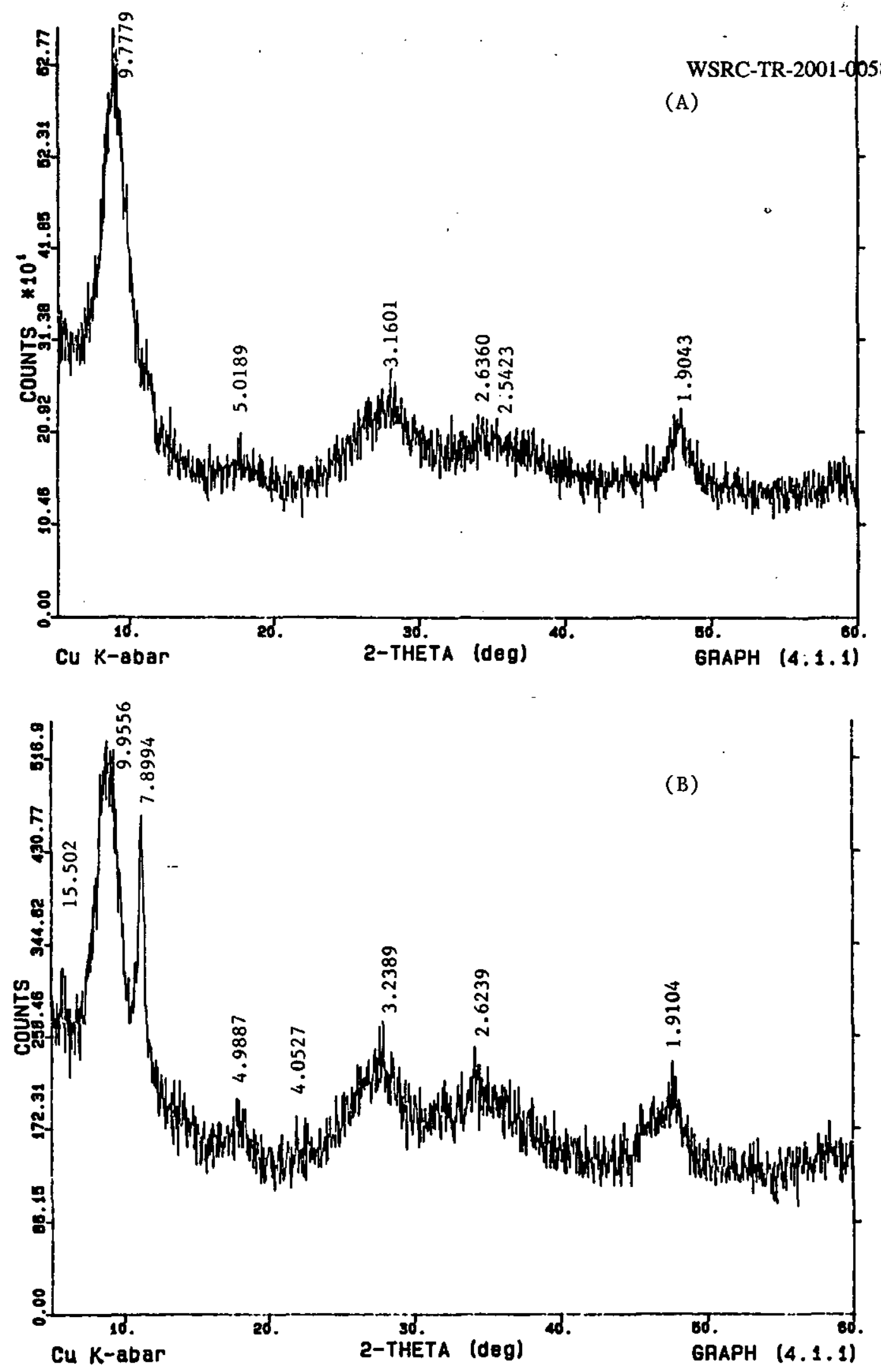

$\mathrm{X}$-ray powder patterns of solids obtained during examination of heating time in preparation of the CST, $\mathrm{Na}_{2} \mathrm{Ti}_{2} \mathrm{O}_{3} \mathrm{SiO}_{4} \cdot 2 \mathrm{H}_{2} \mathrm{O}$; (A) Unknown precursor phase formed after one hour at $200^{\circ} \mathrm{C},{ }^{2}$ and (B) After ten hours heating a mixture of the precursor phase and CST is obtained as shown by the narrow peak at $7.89 \AA$.

Figure 9 


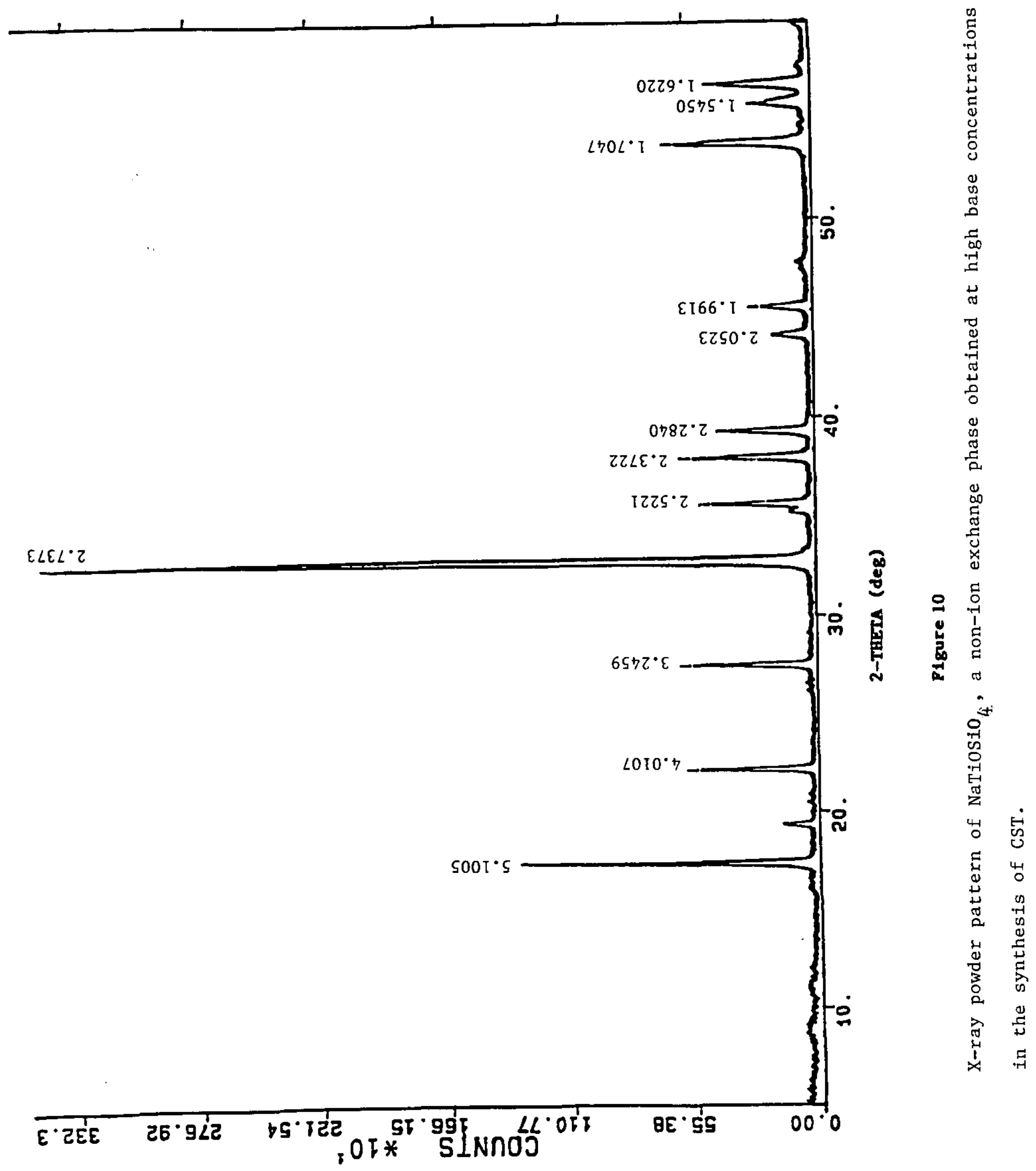


Figure 11

Kinetic studies of sorption of Str+ on TS DM1-13-1 and DM1-13-2. Simulan: $0.0075 \mathrm{M} \mathrm{Ca}^{2+}, 0.04 \mathrm{M} \mathrm{Na}^{+}, 0.025 \mathrm{M} \mathrm{K}^{*}, \mathrm{Sr}^{2+}$, traces
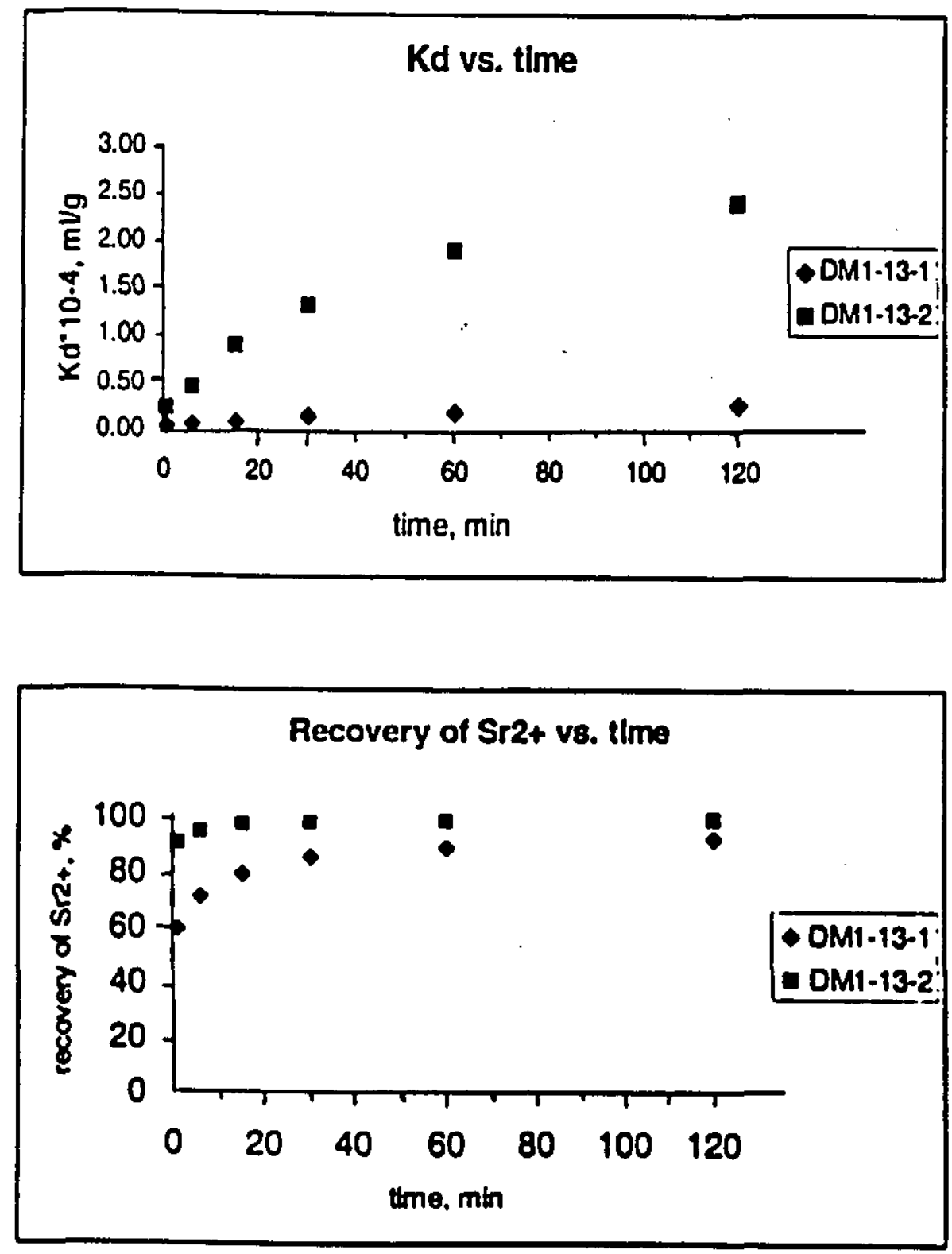

Kinetic curves for strontium exchange from a simulant for a highly crystalline CST sample DM1-13-1, and a poorly crystalline sample DMl-13-2. 
Figure 12

\begin{tabular}{|c|c|c|}
\hline time, $\mathrm{h}$ & $\begin{array}{c}\mathrm{Kd \times 10^{- }} \\
\mathrm{mV} / \mathrm{g}\end{array}$ & $\begin{array}{c}\text { recovery of Sr2t, } \\
\%\end{array}$ \\
\hline 0.083 & 0.1015 & 80.3 \\
\hline 0.5 & 0.6669 & 96.43 \\
\hline 1 & 1.372 & 98.21 \\
\hline 5 & 3.1342 & 99.22 \\
\hline 24 & 5.0874 & 99.52 \\
\hline 47 & 5.3710 & 99.54 \\
\hline
\end{tabular}

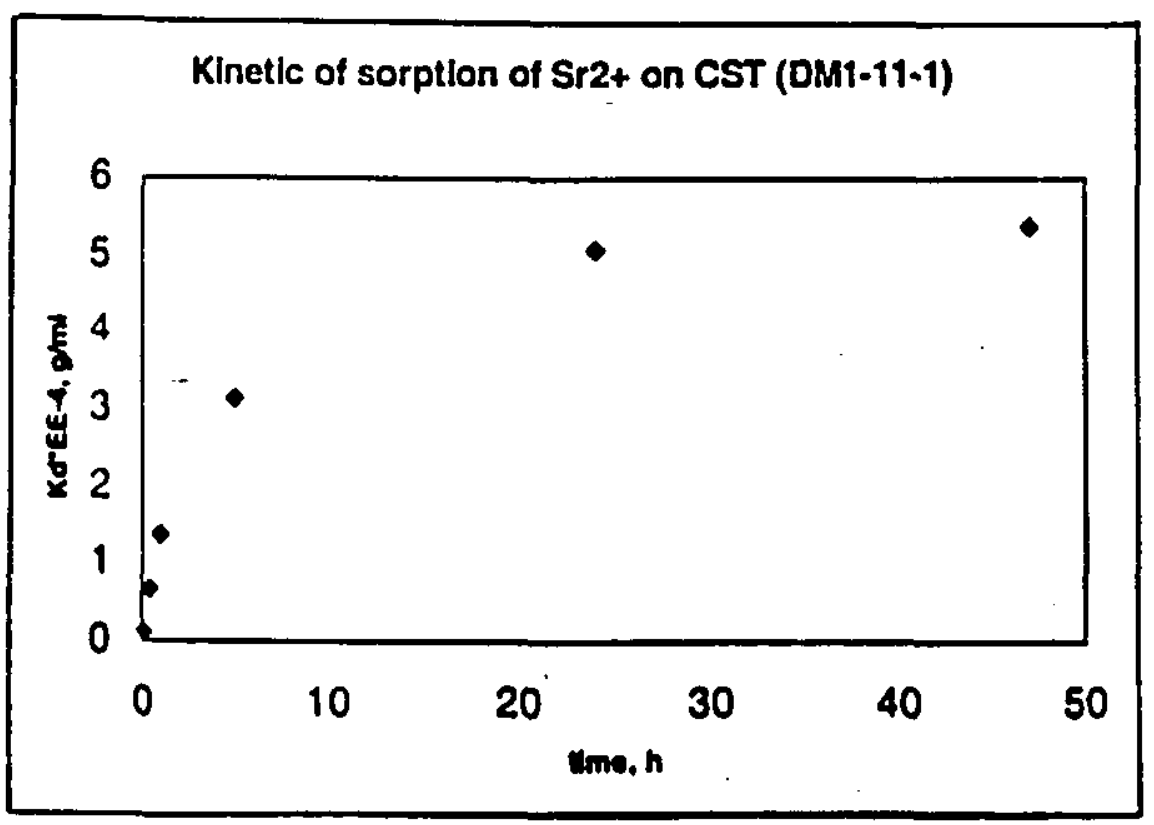

Kinetics of $\mathrm{Sr}^{2+}$ uptake by a poorly crystalline CST sample DM1-11-1 submitted for testing at WSRC. 


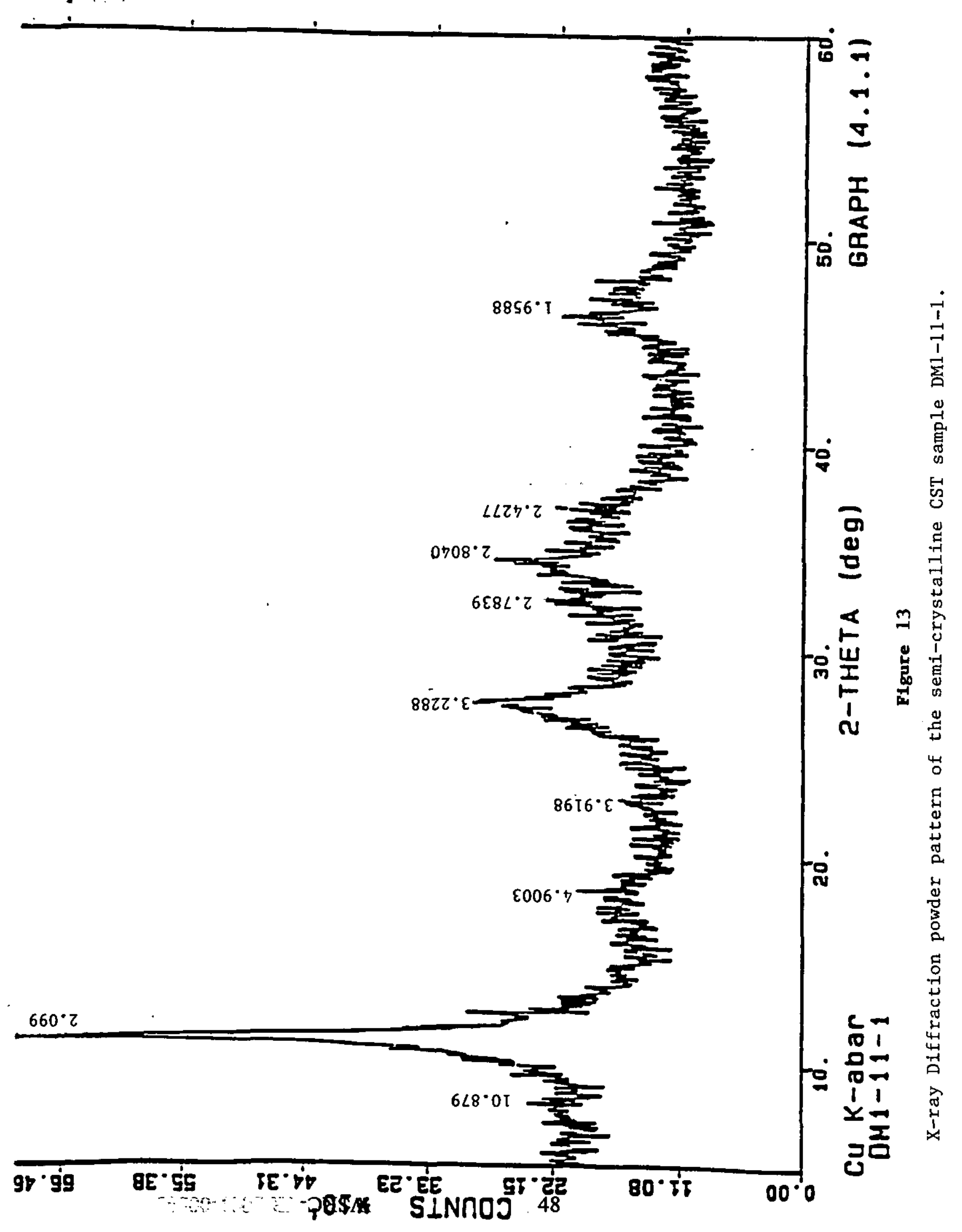


WSRC-TR-2001-00583

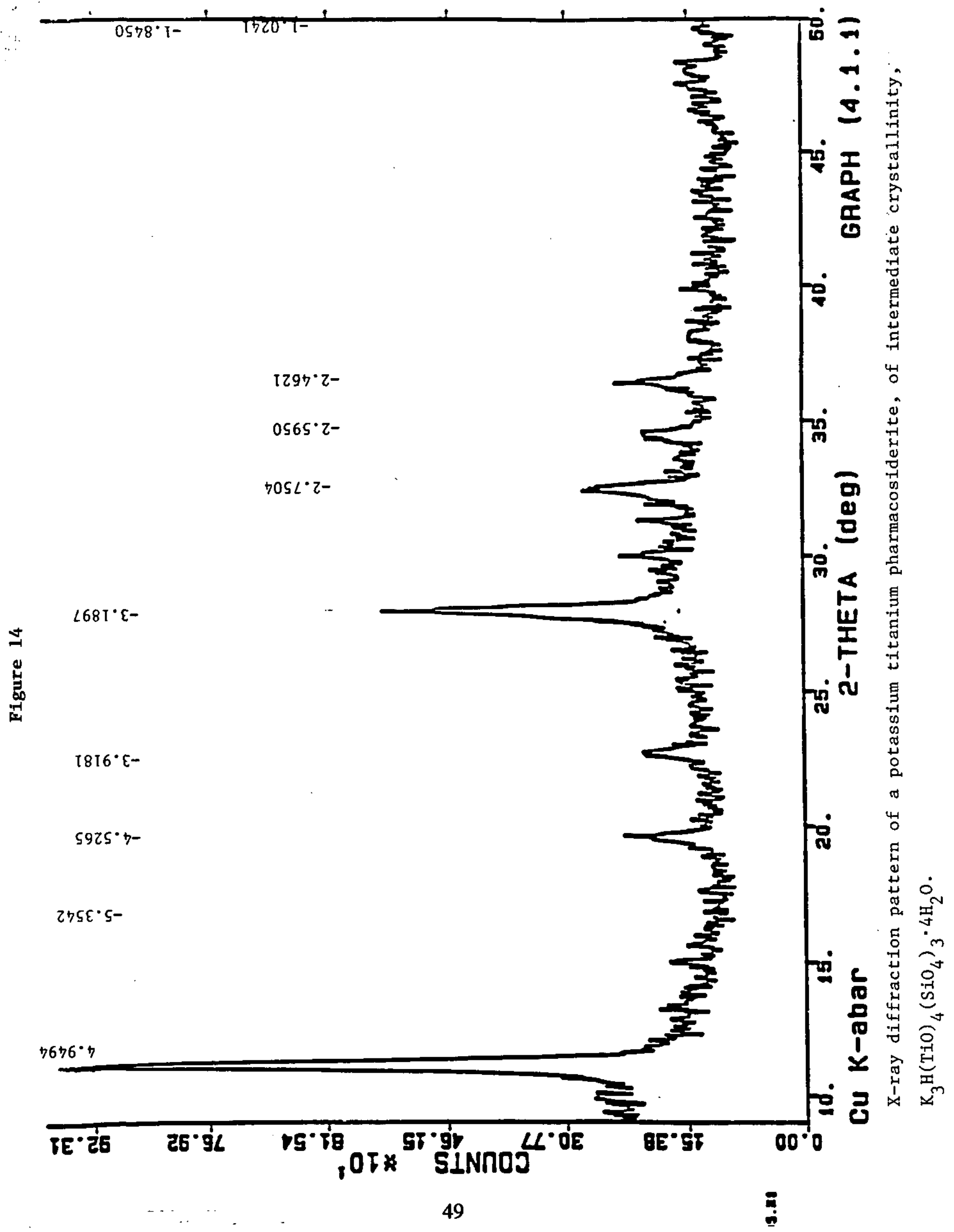



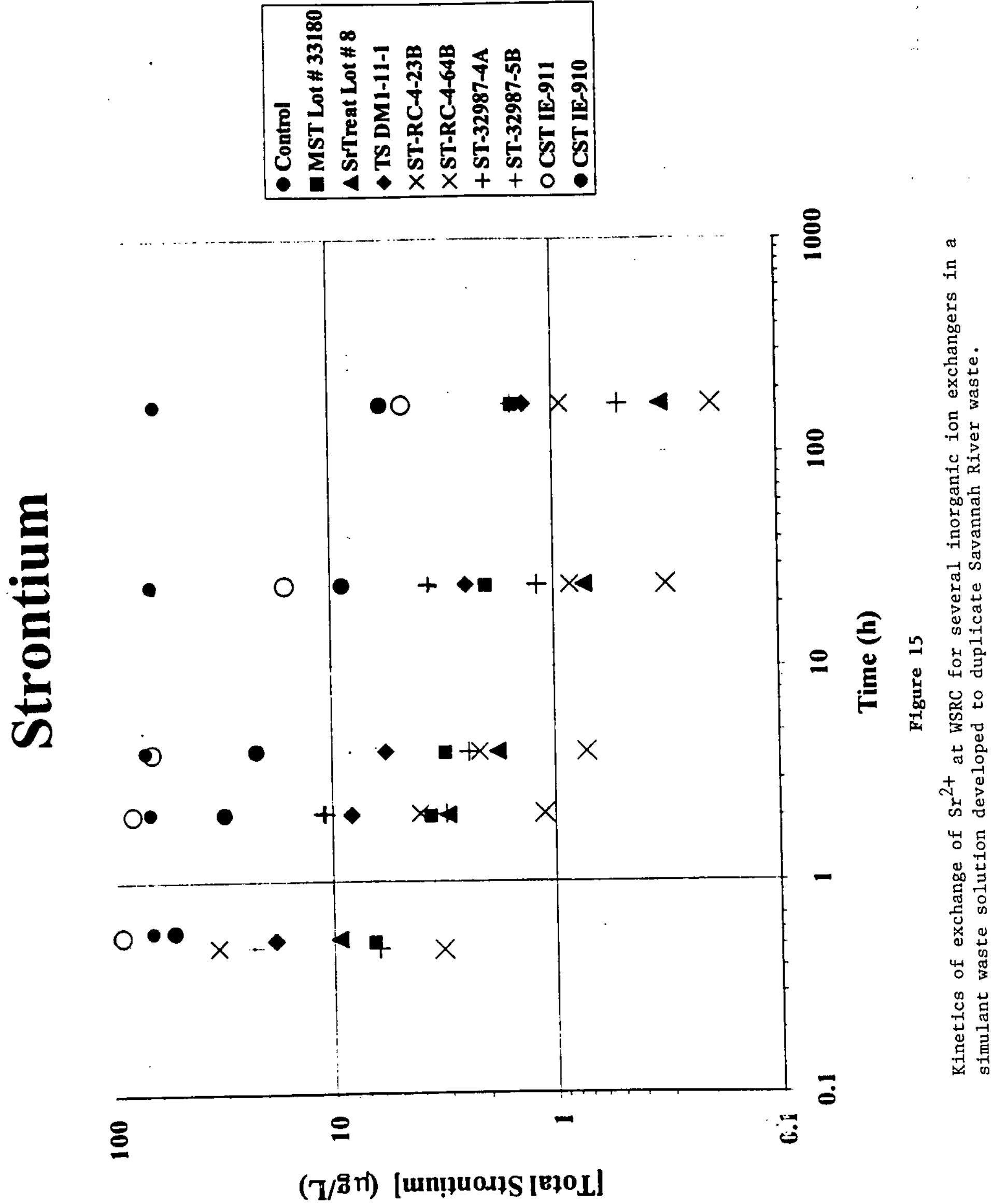
WSRC-TR-2001-00583

Figure 16a. Plutonium Removal with Sodium Nonatitanate and Monosodium Titanate Samples

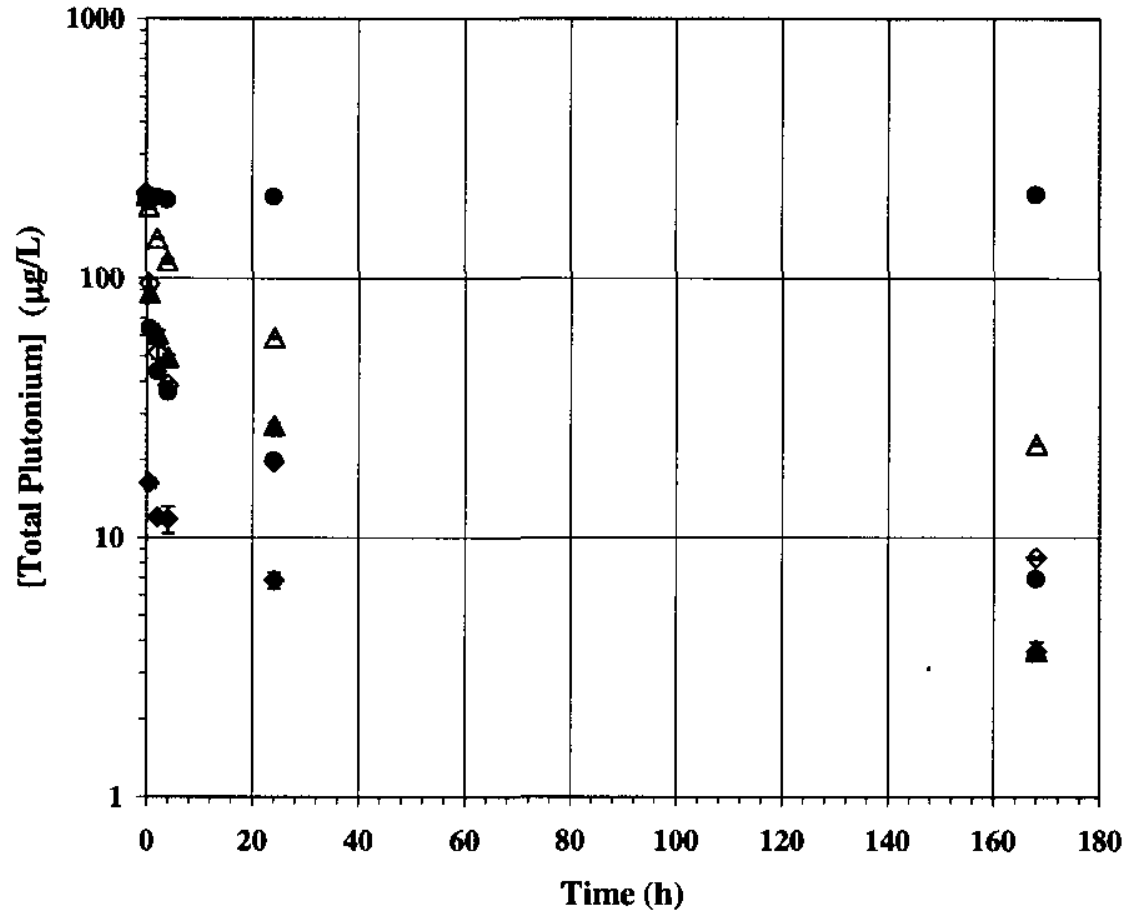

- Control

- MST Lot \# 33180

$\triangle$ ST-RC-4-23B

$\triangle$ ST-RC-4-64B

$\diamond$ ST-39287-5A

- ST-39287-5B

Figure 16b. Neptunium Removal with Sodium Nonatitanate and Monosodium Titanate Samples

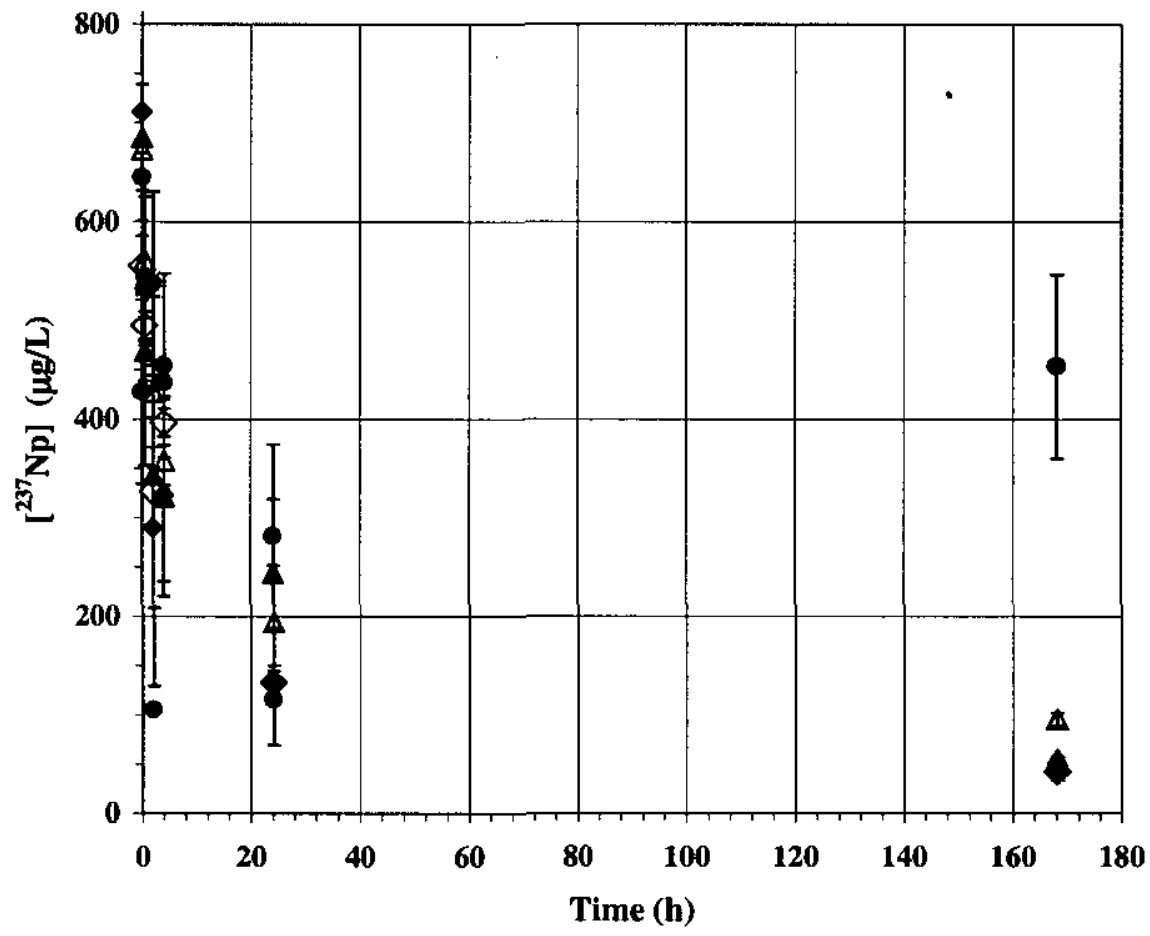

- Control

- MST Lot \# 33180

$\triangle$ ST-RC-4-23B

$\triangle$ ST-RC-4-64B

$\checkmark$ ST-39287-5A

- ST-39287-5B

Kinetic measurements for (A) plutonium uptake and (B) Neptunium uptake as a function of time for several sodium nonatitanates in SR waste simulant. Work performed at WSRC. 


\section{DISTRIBUTION:}

Bob Adams, 704-3N(E)

M. J. Barnes, 773-A(E)

S. G. Campbell, 704-196N(E)

J. T. Carter, 704-3N(P)

N. F. Chapman, 704-3N(P)

W. D. Clark, 704-3N(E)

Jack Collins, ORNL(P)

Troy Donahue, 241-109F(E)

M. C. Duff, 773-A(E)

R. E. Edwards, 704-3N(P)

H. H. Elder, 704-196N(E,P)

S. D. Fink, 773-A(E,P)

F. F. Fondeur, 773-A(E)

H. D. Harmon, 704-3N(P)

R. N. Hinds, 704-3N(E)

D. T. Hobbs, 773-A(E)

E. W. Holtzscheiter, 773-A(E)

W. M. Howell, 704-196N(E)

T. M. Jones, 999-W(E)

R. T. Jones, 704-3N(E,P)

V. G. Kay, 704-3N(E)

Leon Klatt, ORNL(P)

K. C. Kwon, 704-196N(P)

D. P. Lambert, 773-A(E)

R. Leugemors, PNNL(P)

B. L. Lewis, 704-S(E,P)

T. J. Lex, 703-H(E)

J. C. Marra, 773-43A(E)

C. J. Martino, 773-A(E)

George Mathis, 704-K(E)

J. W. McCullough, 704-3N(E)

J. P. Morin, 703-H(E)

B. A. Moyer, ORNL(P)

M. A. Norato, 786-5A(E)
Mike Norton, 704-3N(P)

L. M. Nelson, 773-43A(E)

Tor Osmundsen, 704-3N(E)

L. M. Papouchado, 773-A(P)

T. B. Peters, 773-42A(E)

R. A. Pierce, 773-A(E)

J. A. Pike, 704-196N(E))

M. R. Poirier, 773-42A(E,P)

T. J. Spears, 704-3N(E)

R. H. Spires, 773-A(E)

M. E. Stallings, 773-A(E)

W. E. Stevens, 773-A(E)

S. G. Subosits, 704-196N(E)

P. C. Suggs, 704-196N(P)

W. L. Tamosaitis, 773-A(P)

G. A. Taylor, 704-196N(E)

M. C. Thompson, 773-A(E)

W. B. Van Pelt, 773-42A(E)

D. D. Walker, 773-A(E)

F. A. Washburn, 704-196N(E)

W. R. Wilmarth, 773-42A(P)

STI, 703-43A(4 copies)(E,P)

LWP Files c/o Cathy Canada, 773-42A(E,P)

ITP Files c/o Cathy Smalis, 241-147H(E)

Tanks Focus Area Technical Team, c/o

B.J. Williams, Pacific Northwest National Lab

P.O. Box 999, MSIN K9-69, Richland, WA 99352(P)

Tanks Focus Area Program Lead, c/o T.P. Pietrok, US Dept of Energy, Richland Operations Office, P.O. Box 550, MS: K8-50, Richland, WA 99352(P)

Tanks Focus Area Headquarters Program Manager, C/o K.D. Gerdes, DOE Office of Science and Technology, 19901 Germantown Rd. 1154 Cloverleaf Bldg., Germantown, MD, 20874-1290(P)

\section{(E) Electronic \\ (P) Paper Mail}

